\title{
Target intensity and interval walking training in water to enhance physical fitness in middle-aged and older women: a randomised controlled study
}

Shuichi Handa ${ }^{1,3}$, Shizue Masuki ${ }^{1,2}$, Takuya Ohshio ${ }^{1,3}$, Yoshi-ichiro Kamijo ${ }^{1,2}$, Akira Takamata $^{4}$, and Hiroshi Nose ${ }^{1,2}$

${ }^{1}$ Deptartment of Sports Medical Sciences, Shinshu University Graduate School of Medicine and ${ }^{2}$ Institute for Biomedical Sciences, Shinshu University, Matsumoto 390-8621, ${ }^{3}$ Mimaki Spa Clinic, Tomi 389-0402, ${ }^{4}$ Department of Environmental Health, Faculty of Human Life and Environment, Nara Women's University, Nara 630-8506, Japan.

Running head: Interval walking training in water

Text: 29 pages

Tables: 3

Figures: 8

Financial support: This study was supported in part by grants from the Ministry of Health, Labor, and Welfare (Comprehensive Research on Aging and Health) and the Japan Society for the Promotion of Science (24240089).

Conflict of interest: No conflicts of interest, financial or otherwise, are declared by the authors.

Address correspondence to:

Hiroshi Nose, M.D., Ph.D.

Department of Sports Medical Sciences,

Shinshu University Graduate School of Medicine,

3-1-1 Asahi Matsumoto 390-8621, Japan.

TEL: +81-263-37-2681

FAX: +81-263-34-6721

e-mail: nosehir@shinshu-u.ac.jp 


\section{ABSTRACT}

Purpose: To determine the target intensity for fast walking during interval walking training (IWT) in water for middle-aged and older people to enhance physical fitness.

Methods: Thirty-one women (59 \pm 5 (SD) years old) were randomly divided into two groups: IWT on land (LG, N=15) and in water (WG, $\mathrm{N}=16)$. All subjects were instructed to perform $\geq 6$ sets of fast and slow walking for 3 min each in a day, $\geq 4$ days $\cdot w^{-e e k^{-1}}$, for 8 weeks, at an intensity $35 \%$ higher than the oxygen consumption rate at the gas exchange threshold $\left(\mathrm{VO}_{2 \mathrm{GET}}\right)$, with a subjective feeling of 16-18 points of the Borg scale during fast walking in each condition. Before and after IWT, we measured $\mathrm{VO}_{2 \mathrm{GET}}$, peak aerobic capacity $\left(\dot{\mathrm{VO}}_{2 \text { peak }}\right)$ by graded walking and cycling tests on land and isometric knee extension ( $\left.\mathrm{F}_{\mathrm{EXT}}\right)$ and flexion (FFLX) forces.

Results: Before IWT, the $\mathrm{VO}_{2 \mathrm{GET}}$ for walking in water was $14 \%$ higher and the heart rate (HR) at a given $\mathrm{VO}_{2}$ was $\sim 10$ beats $\cdot \min ^{-1}$ lower $(\mathrm{P}=0.001)$ than on land. During IWT, subjects in both groups performed IWT for $\sim 4$ days $^{\cdot}$ week $^{-1}(\mathrm{P}>0.9)$ with a $14 \%$ higher fast walking intensity in WG than in $\mathrm{LG}(\mathrm{P}<0.05)$. After IWT, the $\mathrm{VO}_{2 \text { peak }}$ and $\dot{\mathrm{VO}}_{2 \mathrm{GET}}$ for cycling, $\mathrm{F}_{\text {EXT }}$ and $\mathrm{F}_{\mathrm{FLX}}$ increased more in WG than in LG (all, $\left.\mathrm{P}<0.05\right)$.

Conclusion: Walking in water elevated $\mathrm{VO}_{2 \mathrm{GET}}$ and decreased $\mathrm{HR}$ at a given exercise intensity in middle-aged and older women, which enabled them to perform exercise at a higher metabolic rate than on land due to improved subjective feelings, which, for these subjects, resulted in greater gains in physical fitness.

Key words: middle-aged and older women; exercise training; head-out water immersion; peak aerobic capacity; thigh muscle strength 


\begin{tabular}{|c|c|}
\hline \multicolumn{2}{|c|}{ Abbreviations } \\
\hline BMI & Body mass index \\
\hline DBP & Diastolic blood pressure \\
\hline $\mathrm{F}_{\mathrm{EXT}}$ & Knee extension force \\
\hline $\mathrm{F}_{\mathrm{FLX}}$ & Knee flexion force \\
\hline GET & Gas exchange threshold \\
\hline HR & Heart rate \\
\hline $\mathrm{HR}_{\mathrm{GET}}$ & HR at GET \\
\hline $\mathrm{HR}_{\text {peak }}$ & $\mathrm{HR}$ at $\dot{\mathrm{VO}}_{2 \text { peak }}$ \\
\hline IWT & Interval walking training \\
\hline LG & Land group \\
\hline SBP & Systolic blood pressure \\
\hline$\dot{\mathrm{VCO}}_{2}$ & Carbon dioxide production rate \\
\hline VM & Vector magnitude of tri-axial accelerations \\
\hline $\mathrm{VO}_{2}$ & Oxygen consumption rate \\
\hline $\mathrm{VO}_{2 \mathrm{GET}}$ & $\mathrm{VO}_{2}$ at GET \\
\hline$\dot{\mathrm{VO}}_{2 \text { peak }}$ & Peak oxygen consumption rate \\
\hline WG & Water group \\
\hline
\end{tabular}




\section{INTRODUCTION}

Exercise training at a higher intensity relative to the individual maximal aerobic capacity has been recommended for middle-aged and older people to prevent physical fitness deterioration with advanced ageing and associated diseases (American College of Sports Medicine 2010). However, with ageing, gradually reduced muscle strength in the lower extremities occurs, frequently accompanied by knee pain (Muraki et al. 2009), which may make it difficult for middle-aged and older people to perform exercise training, especially at higher intensities.

Aquatic exercise has been highlighted as a countermeasure against fitness deterioration because reduced body weight due to buoyancy in water may decrease the load on knee joints to relieve pain if they have (Bartels et al. 2007; Harrison et al. 1992). In addition, increased venous return to the heart with head-out water immersion (Park et al. 1999), and thereby increased cardiac stroke volume (Christie et al. 1990), may attenuate an increase in plasma lactate concentration during exercise training (Connelly et al. 1990). All of these may decrease the subjective feeling of exercise intensity and the rating of perceived exertion (RPE), which may make it easier for older people to perform walking training in water; however, walking training studies in water have typically been conducted with less attention paid to exercise intensity relative to individual maximal aerobic capacity compared with that on land (Bocalini et al. 2008; Ide et al. 2008; Sanders et al. 2013; Tsourlou et al. 2006).

To date, the target intensity for exercise training in water has been determined according to age-predicted maximal heart rate (HR) (Bocalini et al. 2008; Tsourlou et al. 2006) or lactate threshold determined by graded cycling exercise on land (Takeshima et al. 2002); however, these variables might change in water (Christie et al. 1990; 
Connelly et al. 1990; Park et al. 1999). In addition, recently, since aquatic treadmills have become available, attempts using the equipment have been made to determine the walking velocity that is equivalent to the target intensity for walking training in water (Hall et al. 2004; Lim and Rhi 2014); however, rheological resistance against body movement to the forth direction is minimal when walking on a treadmill compared with that in a pool where most people currently perform walking training. Thus, the variables determined by graded exercise on land or the walking velocity determined by walking on an aquatic treadmill might not represent an adequate target intensity for walking training in a pool that would maximize the physical fitness effects.

Therefore, the present study was conducted to solve this problem. Fig. 1 shows our experimental strategy for the present study during the last decade. First, we developed a field-based exercise training system according to individual peak aerobic capacity ( $\mathrm{VO}_{2 \text { peak }}$ for walking on land, which can be made broadly available for middle-aged and older people at low cost, without visiting a gym to use machines, bicycles or treadmills, and with less technical and personnel support (Nose et al. 2009).

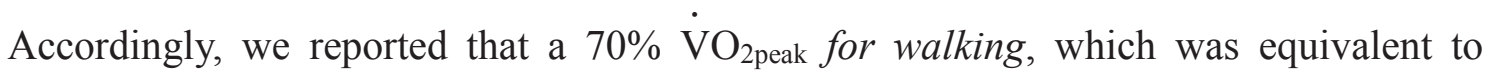
$\sim 35 \%$ higher than the gas exchange threshold (GET) for most middle-aged and older subjects, could be used to determine a target intensity for interval walking training (IWT) for 20 weeks on land to increase thigh muscle strength and the $\dot{\mathrm{VO}}_{2 \text { peak }}$ by $\sim 10 \%$ (Nemoto et al. 2007) and to decrease lifestyle-related risk factors by $20 \%$ (Masuki et al. 2010 \& 2015; Morikawa et al. 2011). However, no study has previously evaluated the target intensity of IWT in water.

Based on these previous studies, in the present study, we specifically hypothesized that the target intensity derived from the GET during walking in water would be 
higher than on land because lactate concentration in plasma and HR at a given intensity was reported to decrease during exercise in water compared with on land (Christie et al. 1990; Connelly et al. 1990; Park et al. 1999). In addition, we hypothesized that subjects would accomplish an 8-week walking training in water with a higher target intensity than on land and whether their physical fitness increased more. If these hypotheses are supported, the information will be helpful for middle-aged and older people who are planning to perform IWT in water to enhance their fitness.

\section{METHODS}

\section{Subjects and Protocol}

In March 2013, we recruited subjects by announcing the study to 10,600 households in Tomi via a city bulletin. The study protocol was approved by the Review Board of Human Experiments of the Shinshu University School of Medicine. After explaining the protocol to the 42 responders, 34 subjects, who were all non-smokers, gave written informed consent and agreed to participate in the study. In general, the subjects had a sedentary lifestyle, and had not undergone any particular exercise training programme before participating in the present study. After interviewing the subjects about their past and current health status using questionnaires in our clinic (Mimaki Spa Clinic, Tomi, Japan), we measured their height, body mass, and body fat by bioelectrical impedance analysis (BF-800; Tanita, Tokyo, Japan) in a gym (15 m x 15 m) located in the clinic. Systolic (SBP) and diastolic (DBP) blood pressure data were also measured by auscultation after a 10-min resting period. On separate days, we measured isometric knee extension $\left(\mathrm{F}_{\mathrm{EXT}}\right)$ and flexion $\left(\mathrm{F}_{\mathrm{FLX}}\right)$ forces, and then, more than 24 hours later, we measured GET and $\dot{\mathrm{VO}}_{2 \text { peak }}$ during a graded cycling exercise, 
and further, more than 48 hours later, we measured $\mathrm{VO}_{2 \text { peak }}$ during a graded walking exercise on land for all subjects in both groups. The details of the measurements are described below.

As in Fig. 2, we randomly divided the 34 subjects equally into the land (LG) and water (WG) groups, which performed IWT on the land or in water, respectively. Due to staff and training instruments limitations, we further divided each group into $1^{\text {st }}$ and $2^{\text {nd }}$ subgroups, starting the IWT in April 2013 and in August 2013, respectively. In addition, for the $\mathrm{WG}$, we also measured the GET and $\mathrm{VO}_{2 \text { peak }}$ during a graded water walking exercise in a pool. After the 8-week IWT protocol, we measured the same variables as before the training.

The atmospheric temperature in the gym and in the pool area was $20-27^{\circ} \mathrm{C}$ and $25-34^{\circ} \mathrm{C}$, respectively, while the relative humidity in the gym and in the pool area was $20-60 \%$ and $22-78 \%$, respectively. The water temperature in the pool was $31{ }^{\circ} \mathrm{C}$.

A subject from the LG abandoned the training protocol due to health issues, and another subject was absent from the second follow-up measurement session after the training. In addition, a subject in the WG abandoned the training due to family issues. Therefore, we analysed the results in a total of 15 and 16 subjects in the LG and WG, respectively. They accomplished the training protocols without any harmful events. The physical characteristics of the subjects are presented in Table $\mathbf{1}$ and Table $\mathbf{2}$.

\section{Measurements}

$\underline{\mathrm{VO}}_{2 \text { peak }}$ during a graded cycling test

We determined $\dot{\mathrm{VO}}_{2 \text { peak }}$ by the graded cycling test in an upright position for all subjects (Ergomedic825E; Monark, Stockholm, Sweden) on a flat floor (land) in the 
gym to confirm the reliability of the value separately determined by the graded walking test on land as described below. After the baseline measurements at rest for $3 \mathrm{~min}$, the subjects started pedalling at 60 cycles $\cdot \mathrm{min}^{-1}$ without loading for $3 \mathrm{~min}$ and then at 15 watts for another $3 \mathrm{~min}$. The intensity was increased in 15 watt increments every $2 \mathrm{~min}$ until exhaustion. During the exercise, we measured the oxygen consumption rate $\left(\dot{\mathrm{VO}}_{2}\right)$ and the carbon dioxide production rate $\left(\mathrm{VCO}_{2}\right)$ of every breath using a respiratory gas analyser (Metamax3B; Cortex, Leipzig, Germany). HR was recorded using an ECG (Polar; Vantage NV, Kempele, Finland). The measurements were averaged every $10 \mathrm{sec}$ and recorded. The criteria for judging whether exercise intensity reached peak values were that 1 ) subjects were not able to maintain a rhythm of 60 cycles $\cdot \mathrm{min}^{-1}$ or that 2) the respiratory quotient (RQ) increased to over $1.1 . \dot{\mathrm{VO}}_{2 \text { peak }}$ was determined by averaging the three highest consecutive values at the end of exercise. We confirmed that the RQ values at $\mathrm{VO}_{2 \text { peak }}$ were $1.25 \pm 0.02$ and $1.26 \pm 0.031 \cdot \mathrm{min}^{-1}$ in the $\mathrm{LG}$ and $1.21 \pm 0.03$ and $1.18 \pm 0.021 \cdot \mathrm{min}^{-1}$ in the WG before and after training, respectively, which was significantly higher than 1.1 (all, $\mathrm{P}<0.0001$ ), and there were no significant differences between the measurements (all, $\mathrm{P}>0.1$ ).

The $\dot{\mathrm{VO}}_{2}$ at GET $\left(\dot{\mathrm{VO}}_{2 \mathrm{GET}}\right)$ was determined by three investigators who did not know to which groups the subjects belonged based on a profile of $\dot{\mathrm{VCO}}_{2}$ response to $\mathrm{VO}_{2}$ averaged every $10 \mathrm{sec}$ throughout the test using the V slope method (Beaver et al. 1986), and the intermediate value of the three values was adopted.

\section{$\underline{\mathrm{VO}_{2 p e a k} \text { during a graded walking test on land and in water }}$}

We measured $\dot{\mathrm{VO}}_{2 \text { peak }}$ for walking in all subjects on land and in water, respectively, by a graded walking test. At first, they walked on a flat floor in the gym at four 
subjectively graded velocities — at rest, slow, moderate and the fastest, equivalent to $\sim 6$, $\sim 11, \sim 14$, and $\sim 19$ points of the Borg Scale (RPE) — for a period of 3 min at each speed. During the fastest walking, subjects were encouraged by the investigators with cheer and clap their hands to reach their maximal velocity. Although the velocity varied according to the subjects, they were assumed to be $0, \sim 50, \sim 75$, and $\sim 100 \mathrm{~m} \cdot \mathrm{min}^{-1}$, respectively, on average (Yamazaki et al. 2009). Then, after they were randomly divided into the LG and WG, the subjects in the WG underwent a similar test in the pool while immersed in water up to the xiphoid process ( $25 \mathrm{~m}$ pool, $\sim 110 \mathrm{~cm}$ from the bottom).

During the test, in both conditions, the $\dot{\mathrm{VO}}_{2}, \dot{\mathrm{V} C O}$, and $\mathrm{HR}$ were measured with the same devices as during the graded cycling test (Fig. 3). In addition, the accelerations were measured every $5 \mathrm{sec}$ using a tri-axial accelerometer (JD Mate; Kissei Comtec, Matsumoto, Japan). During the test on land, the accelerometer was carried on the mid-clavicular line of the right waist, whereas during the test in the pool, it was carried on the occipital region of the head to avoid getting wet. Additionally, during the test on land, the devices used for measuring the respiratory gas, weighing $\sim 800 \mathrm{~g}$, were carried on the shoulders of the subjects. On the other hand, during the test in the pool, the devices were placed in a butterfly net and carried by the staff walking outside of the pool alongside the subjects walking in the pool; accordingly, the devices could be located above the subjects head without getting wet.

Fig. 3A shows a trend graph of the $\mathrm{HR}, \dot{\mathrm{VO}}_{2}$, and $\dot{\mathrm{VCO}}_{2}$ responses of the subjects during the graded walking tests. The $\dot{\mathrm{VO}}_{2 \text { peak }}$ and $\mathrm{HR}$ peak $\left(\mathrm{HR}_{\text {peak }}\right)$ for the land and water walking tests were determined by averaging the three highest consecutive values at the end of exercise. Then, as in Fig. 3B (lower), the $\dot{\mathrm{VO}}_{2 \mathrm{GET}}$ was determined from a profile of $\dot{\mathrm{VCO}}_{2}$ response to $\dot{\mathrm{VO}}_{2}$ averaged every $10 \mathrm{sec}$ throughout the test for $12 \mathrm{~min}$, 
as in the graded cycling test (Beaver et al. 1986). Finally, $\mathrm{HR}$ at a given $\mathrm{VO}_{2}$ at rest, GET $\left(\mathrm{HR}_{\mathrm{GET}}\right)$, and the highest common $\dot{\mathrm{VO}}_{2}$ observed in both conditions, which was lower $\mathrm{VO}_{2 \text { peak }}$ level of the two conditions, were compared between the two conditions, according to the procedure shown in Fig. 3B (upper). These results are summarised in

\section{Fig. 4 \& Table 2.}

The measurements averaged every min were also used to determine the regression equations used to estimate the $\dot{\mathrm{VO}}_{2}$ from the vector magnitude (VM, G) of the accelerations measured during the IWT on land for the LG (Yamazaki et al. 2009) and in water for the WG (Fig. 5).

\section{Thigh muscle strength}

We measured the $\mathrm{F}_{\mathrm{EXT}}$ and $\mathrm{F}_{\mathrm{FLX}}$ on the dominant side of the leg with an isometric force metre (GT330; OG Giken, Okayama, Japan) in duplicate while the knee angle was fixed to 60 degrees; the highest value was used in the analysis. The measurements were performed by the staff members, who remained unaware of the group assigned to the evaluated subjects.

\section{Training for $W G$}

The subjects were instructed to repeat 6 sets of fast and slow walking $3 \mathrm{~min}$ intervals in the same pool as for the pre-training test while immersed in water up to the xiphoid process and to perform that training session for more than 4 days ${ }^{*}$ week $^{-1}$ for a period of 8 weeks. We allocated the pool for subjects at 3 times a day-12:00-13:00, 18:00-19:00, and 20:30-21:30 — 5 days a week, from Tue to Sat, allowing them to freely use the pool one time a day on more than 4 days a week, according to their convenience. 
The target intensity for the fast walking intervals was $35 \%$ higher than the $\dot{\mathrm{VO}}_{2 \mathrm{GET}}$ determined by graded walking in water before the training. We instructed subjects to perform fast and slow walking of IWT above and below the target intensity, respectively, with subjective feeling of 16-18 and 10-12 points for the Borg Scale, respectively. In the WG, the target intensity was $1.26 \pm 0.11 \cdot \mathrm{min}^{-1}$, which is equivalent to $91 \%$ of the

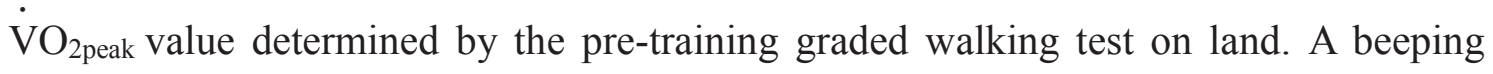
signal from a JD Mate device alerted the subjects when a change of intensity was scheduled, and another melody informed them when more than the target intensity level was attained. Energy expenditure data, monitored with the JD Mate device carried on the occipital region of head during training, are presented in Table 3.

After the start of training, subjects visited the clinic every week, and the data from the JD Mate devices were transferred over the internet to a server located in the administrative centre and received the evaluation for their achievement from the server (Nose et al. 2009).

\section{Training for $L G$}

The subjects in both LG subgroups performed IWT in the same period as those in their corresponding WG subgroup. After the graded walking test, the subjects were instructed to repeat 6 sets of 3 min fast and slow walking intervals per day, for more than 4 days ${ }^{*}$ week $^{-1}$ during 8 weeks. To accomplish this, similar to the WG training, we allocated the gym to subjects 3 times per day 5 days a week, allowing them to freely use the gym one time a day more than 4 days a week, according to their convenience.

The target intensity for the fast walking intervals was $35 \%$ higher than the $\mathrm{VO}_{2 \mathrm{GET}}$ value determined during the pre-training graded walking test on land. We instructed 
subjects to perform fast and slow walking of IWT as in the WG. For the LG, the target intensity was $1.09 \pm 0.1 \mathrm{l} \cdot \mathrm{min}^{-1}$, equivalent to $76 \%$ of the pre-training $\mathrm{VO}_{2 \text { peak }}$ for walking. The subject's energy expenditure during training was monitored using a JD Mate device carried on the mid-clavicular line of the right waist. These data are presented in Table 3. Subjects visited the clinic every week, and the data from their JD Mate device were transferred over the internet to a server in the administrative centre and received the evaluation for their achievement from the server (Nose et al. 2009).

\section{Statistical analyses}

A one-way ANOVA for the repeated measures was used to determine the significant differences in the slopes and the intercepts of regression equations for $\mathrm{VO}_{2}$ versus $\mathrm{HR}$. The model was also used to examine the significant differences in $\mathrm{HR}$ at a given $\mathrm{VO}_{2}$ between on land and in water; at rest, GET, and the highest common $\mathrm{VO}_{2}$ observed in both conditions during the graded walking test (Fig. 4). Further, this model was used to determine the significance in the inter-group differences observed for the training achievements (Table 3).

A two-way [(before and after training) x groups] ANOVA for repeated measures was used to determine the significant differences in the physical characteristics (Table 1), $\mathrm{HR}_{\text {peak }}, \dot{\mathrm{VO}}_{2 \text { peak, }}, \mathrm{HR}_{\mathrm{GET}}$ and $\dot{\mathrm{VO}}_{2 \mathrm{GET}}$ (Table 2) between before and after training and between groups, with a significant interactive effect of [(before and after training) $\mathrm{x}$ group] on these variables. This model was also used to determine the significant differences in the fast walking $\mathrm{VO}_{2}$ values over time during the training weeks and between the groups (Fig. 6) and the significant differences in FEXT and FFLX (Figs. 7A \& B) before and after training and between groups, with a significant interactive effect of 
[(training weeks) or (before and after training) $\mathrm{x}$ groups] on these variables. After confirming the significant differences using ANOVA, a Tukey-Kramer test was used as a post-hoc test to determine the significant differences in pairwise comparisons. Values are presented as the mean and standard error (SE). The null hypothesis was rejected when $\mathrm{P}<0.05$.

The standard regression analysis was used to determine the regression equations between VM versus $\dot{\mathrm{VO}}_{2}$ with the $95 \%$ confidence limits (Fig. 5) and between $\dot{\mathrm{VO}}_{2}$ versus HR during the graded walking test on land and in water. The analysis was also used to compare $\dot{\mathrm{VO}}_{2 \text { peak }}$ for walking with that for cycling in individual subjects to determine the regression equation with the 95\% confidence limits (Fig. 8).

To examine the possibility of Type II error for the analyses (Cohen 1988), we present the statistical power $(1-\beta)$ in the text, at $\alpha=0.05$ for both groups, when the variables increased significantly after training or when the increases were significantly greater in the WG than in the LG (Table $2 \boldsymbol{\&} \mathbf{3}$ ). In addition, we present the effect size $\left(\eta^{2}\right)$ in the text at $\alpha=0.05$ in the comparisons of the key variables in the present study, $\dot{\mathrm{VO}} 2$ peak between for walking and for cycling (Table 2), HR at a given $\dot{\mathrm{VO}}_{2}$ and $\dot{\mathrm{VO}}_{2 \mathrm{GET}}$ during the graded walking test between in water and on land (Fig. 4 \& Table 2), and the exercise intensity for fast walking during training between the WG and LG (Fig. 6).

\section{RESULTS}

Pre-training physical characteristics of the subjects before training

As presented on the left columns for each group in Table 1, there was no significant difference in height, body mass, body mass index (BMI), body fat, SBP, or DBP between the LG and the WG before training. Similarly, as shown in the left/upper 
columns in Table 2, there were no significant differences in $\mathrm{HR}_{\text {peak }}, \dot{\mathrm{VO}}_{\text {2peak }}$ for walking and cycling, $\mathrm{HR}_{\mathrm{GET}}$, and $\dot{\mathrm{VO}}_{2 \mathrm{GET}}$ on land between the $\mathrm{LG}$ and the $\mathrm{WG}$ (all, $\mathrm{P}>0.1$ ).

Relationship between VM versus $\mathrm{VO}_{2}$ during the graded walking test on land and in water

Fig. 5 shows the relationship between the VM $(\mathrm{G})$ and the $\mathrm{VO}_{2}\left(\mathrm{ml} \cdot \mathrm{kg}^{-1} \cdot \mathrm{min}^{-1}\right)$ values during the graded walking test both on land and in water before training. The VM represents the sum of the vector magnitude calculated from the tri-axial accelerations. Before training, the regression equation for walking in water, determined in 16 subjects for the WG, was $\dot{\mathrm{VO}}_{2}(\mathrm{y})=0.187 \mathrm{VM}(\mathrm{x})+4.802\left(\mathrm{R}^{2}=0.807, \mathrm{P}=0.001\right)$ and that for walking on land, determined in 31 subjects pooled from the WG and LG, was $\mathrm{y}=0.055 \mathrm{x}+3.437\left(\mathrm{R}^{2}=0.916, \mathrm{P}=0.001\right)$ with significantly higher slope $(\mathrm{P}<$ $0.001)$ and marginally higher intercept $(\mathrm{P}=0.055)$, in water than on land. We confirmed that the $95 \%$ confidence limit of regression equation was within $\pm 1.0 \mathrm{ml} \cdot \mathrm{kg}^{-1} \cdot \mathrm{min}^{-1}$ for walking in water and $\pm 0.5 \mathrm{ml} \cdot \mathrm{kg}^{-1} \cdot \mathrm{min}^{-1}$ for walking on land over the range of $\mathrm{VM}$ variation. We confirmed this also after training; $\mathrm{y}=0.201 \mathrm{x}+5.244\left(\mathrm{R}^{2}=0.845, \mathrm{P}=\right.$ $0.001)$ in 16 subjects for the WG versus $y=0.056 x+4.076\left(R^{2}=0.888, P=0.001\right)$ in 31 subjects pooled from both groups with a significantly higher slope $(\mathrm{P}<0.001)$ and intercept $(\mathrm{P}=0.012)$ in water than on land (not shown in the figure).

GET and $\mathrm{HR}$ at a given $\mathrm{VO}_{2}$ during graded walking on land and in water

We compared $\mathrm{VO}_{2 \mathrm{GET}}$ during graded walking on land and in water for the WG. As shown in the left/lower column of the WG in Table 2, $\mathrm{VO}_{2 \mathrm{GET}}$ was significantly higher in water than on land before training $(\mathrm{P}<0.01)$, which was also confirmed after training 
$(\mathrm{P}<0.001)$.

We examined whether $\mathrm{HR}$ at a given $\mathrm{VO}_{2}$ was lower in water than on land during the walking test. First, we determined the regression equations between the $\mathrm{VO}_{2}$ and the HR values during the graded walking test, on land and in water, for 16 subjects in the WG before training. The slope determined for 16 subjects was similar in water and on land, $57.4 \pm 3.3$ versus $53.6 \pm 2.9$ beats $\cdot \mathrm{l}^{-1}(\mathrm{P}=0.179)$, while the intercept was significantly lower in water than on land, $54.3 \pm 2.5$ versus $62.5 \pm 1.7$ beats $\cdot \mathrm{min}^{-1}(\mathrm{P}=$ $\left.0.001,1-\beta=0.970, \eta^{2}=0.530\right)$.

Next, we compared the HR response to a given $\dot{\mathrm{VO}}_{2}$ at rest, GET, and the highest common $\mathrm{VO}_{2}$ observed in both conditions. As in Fig. 4, we confirmed that HR at rest was significantly lower in water than on land $\left(P=0.001,1-\beta=0.968, \eta^{2}=0.526\right)($ Fig. 4 left), whereas the $\mathrm{VO}_{2}$ was significantly higher in water than on land $(\mathrm{P}=0.023)$. Furthermore, the $\mathrm{HR}_{\mathrm{GET}}$ in water was similar to that on land $(\mathrm{P}=0.07)$ (Fig. 4 middle), whereas the $\dot{\mathrm{VO}}_{2 \mathrm{GET}}$ was significantly higher in water than on land $(\mathrm{P}=0.001,1-\beta=$ 0.958, $\left.\eta^{2}=0.511\right)\left(\right.$ Table 2). Finally, we found that $\mathrm{HR}$ at the highest common $\dot{\mathrm{VO}}_{2}$ observed in both conditions was significantly lower in water than on land $(\mathrm{P}=0.023$, $\left.1-\beta=0.655, \eta^{2}=0.298\right)$ (Fig. 4 right), with similar $\dot{\mathrm{VO}}_{2}$ measurements $(\mathrm{P}>0.6)$.

In addition, though not shown in the figure, we confirmed these in the WG after training; HR at rest was significantly lower in water than on land, $66 \pm 2$ versus $73 \pm 2$ beats $\cdot \min ^{-1}\left(P<0.001,1-\beta=0.993, \eta^{2}=0.599\right)$ with similar $\mathrm{VO}_{2}$ measurements of 0.26 \pm 0.01 versus $0.25 \pm 0.011 \cdot \mathrm{min}^{-1}(\mathrm{P}>0.08)$. Furthermore, although $\mathrm{HR}_{\mathrm{GET}}$ was slightly but significantly higher in water than on land $(\mathrm{P}=0.012)$, the $\dot{\mathrm{VO}}_{2 \mathrm{GET}}$ was markedly higher in water than on land $\left(P<0.001,1-\beta=0.999, \eta^{2}=0.657\right)$ (Table 2). Finally, HR 
at the highest $\dot{\mathrm{VO}}_{2}$ obtained in both conditions was significantly lower in water than on land, $134 \pm 4$ versus $144 \pm 4$ beats $\cdot \min ^{-1}\left(P<0.001,1-\beta=1.000, \eta^{2}=0.716\right)$, with similar $\dot{\mathrm{VO}} 2$ measurements of $1.54 \pm 0.06$ versus $1.54 \pm 0.061 \cdot \mathrm{min}^{-1}(\mathrm{P}=0.210,1-\beta=$ $\left.0.232, \eta^{2}=0.103\right)$.

These results strongly suggest that $\mathrm{HR}$ at a given $\dot{\mathrm{VO}}_{2}$ was significantly lower in water than on land before and after training.

\section{Training achievements}

Table 3 shows the training achievements in the LG and the WG. The exercise intensity was $13.6 \%(\mathrm{P}=0.023,1-\beta=0.640)$ and $49.3 \%(\mathrm{P}<0.001,1-\beta=1.000)$ higher in the WG than in the LG during the fast walking and slow walking intervals, respectively. In addition, during training, the fast walking time per day was $41.4 \%$ longer $(\mathrm{P}=0.005,1-\beta=0.829)$ and the total $\dot{\mathrm{VO}}_{2}$ value for an 8 -week training period was $36.6 \%$ higher $(\mathrm{P}<0.001,1-\beta=0.985)$ in the WG compared with the LG.

Fig. 6 shows the $\mathrm{VO}_{2}$ values for the fast walking intervals, measured on the last walking day of every week for training. The $\mathrm{VO}_{2}$ values are significantly higher in the WG than in the LG after the $4^{\text {th }}$ week $(\mathrm{P}<0.037,1-\beta>0.563)$, with significant interactive effects of [training weeks x groups] on the variable $(\mathrm{P}=0.005,1-\beta=0.932$, $\left.\eta^{2}=0.094\right)$, suggesting that exercise intensity increased along with advancing training in the WG more than in the LG.

\section{Effects of IWT on land and in water}

As shown for each group in the right columns of Table 1, after training, the body 
mass and BMI decreased in both groups (all, $\mathrm{P}<0.02,1-\beta>0.688$ ), but with no interactive effect of [(before and after training) $\mathrm{x}$ group] on the variables (all, $\mathrm{P}>0.4$ )

As shown for each group in the right/upper columns of Table 2, after training, the $\dot{\mathrm{VO}}_{2 \text { peak }}$ and $\dot{\mathrm{VO}}_{2 \mathrm{GET}}$ values for walking on land and cycling increased in the WG (all, $\mathrm{P}$ $<0.001,1-\beta>0.195)$, while in the LG, only the $\dot{\mathrm{VO}}_{2 \text { peak }}$ for cycling increased $(\mathrm{P}<0.001$, $1-\beta=1.000)$, with a significant interactive effect of [(before and after training) $\mathrm{x}$ groups] on the $\dot{\mathrm{VO}}_{2 \text { peak }}$ and $\dot{\mathrm{VO}}{ }_{2 \mathrm{GET}}$ values only during cycling $(\mathrm{P}<0.03,1-\beta>0.598$, $\eta^{2}>0.153$ ), indicating significantly greater increases in the $\dot{\mathrm{VO}}_{2 \text { peak }}$ and $\dot{\mathrm{VO}}_{2 \mathrm{GET}}$ in the WG than LG. Additionally, as in the right/lower column in Table 2, the $\dot{\mathrm{VO}}$ 2peak for walking in water increased in the WG $(\mathrm{P}=0.001,1-\beta=0.967)$. However, despite the significant increases in $\dot{\mathrm{VO}}_{2 \text { peak }}$ and $\dot{\mathrm{VO}}_{2 \mathrm{GET}}$, the $\mathrm{HR}$ values at $\dot{\mathrm{VO}}_{2 \text { peak }}$ and $\dot{\mathrm{VO}}_{2 \mathrm{GET}}$ remained unchanged after training in the WG and LG (both, $\mathrm{P}>0.3$ ).

Fig. 7A and B show the pre- and post-training FEXT and the FFLX values before and after training for both groups. After training, the FEXT and FFLX in the WG increased by $11.5 \%(\mathrm{P}<0.001,1-\beta=0.985)$ and $11.6 \%(\mathrm{P}<0.001,1-\beta=0.997)$, respectively, while neither increased in the LG (both, $\mathrm{P}>0.3$ ), with significant interactive effects of [(before and after training) $\mathrm{x}$ groups] on both the $\mathrm{F}_{\mathrm{EXT}}(\mathrm{P}=0.028,1-\beta=$ $\left.0.606, \eta^{2}=0.155\right)$ and the $F_{F L X}\left(P=0.001,1-\beta=0.926, \eta^{2}=0.3\right)$, indicating significantly greater increases in the $\mathrm{F}_{\mathrm{EXT}}$ and $\mathrm{F}_{\mathrm{FLX}}$ in the WG than the LG.

VO ${ }_{2 p e a k}$ for walking and cycling

Fig. 8 shows the relationship between $\dot{\mathrm{VO}}_{2 \text { peak }}$ for cycling and walking in both groups before and after training. As shown in the figure, the values were significantly 
correlated $\left(\mathrm{R}^{2}=0.493, \mathrm{P}<0.001\right)$, and the regression equation was $\mathrm{y}=0.85 \mathrm{x}+0.312$, with less than $\pm 0.081 \cdot \mathrm{min}^{-1}$ of $95 \%$ confidence limit over the range of $\dot{\mathrm{VO}}_{2 \text { peak variation, }}$

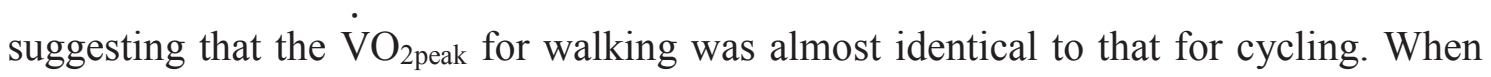
the values from before and after training were pooled, the $\dot{\mathrm{VO}}_{2 \text { peak }}$ for walking was significantly higher than that for cycling- $1.46 \pm 0.03$ versus $1.35 \pm 0.031 \cdot \mathrm{min}^{-1}$, respectively $(\mathrm{P}<0.0001)$.

\section{DISCUSSION}

The major findings of this study are the following: the $\mathrm{HR}$ at a given $\dot{\mathrm{VO}}_{2}$ was lower and the $\dot{\mathrm{VO}}_{2 \mathrm{GET}}$ was higher; therefore, subjects walked at higher intensity at a given RPE; and the overall training effect was greater in water than on land. This is the first study to rigorously quantify and compare land- versus water-based exercise training programs that have been designed to be as comparable as possible and based on detailed individual physiological information.

\section{HR and GET during graded walking on land and in water}

Before the initiation of training, we found that the $\mathrm{HR}$ at a given $\mathrm{VO}_{2}$ during graded walking was reduced in water compared with that on land from the regression analysis between HR versus $\dot{\mathrm{VO}}_{2}$ and also from the HR responses to $\dot{\mathrm{VO}}_{2}$ at rest, $\dot{\mathrm{VO}}_{2 \mathrm{GET}}$, and the highest common $\dot{\mathrm{VO}_{2}}$ observed (Fig. 4). Additionally, we found that $\dot{\mathrm{VO}}_{2 \mathrm{GET}}$ was increased in water compared with that on land. These findings were consistent with the previous results on young subjects for whom cardio-respiratory and plasma lactate concentration responses to graded cycling exercise were compared between on land and in water (Park et al. 1999; Christie et al. 1990; Connelly et al. 1990). As one of the 
mechanisms, it was suggested that the responses in water were caused by increased venous return to the heart with enhanced peripheral venous blood pressure due to the compression of the lower body by water pressure.

The relationship between VM versus $\mathrm{VO}_{2}$ during the graded walking test on land and in water

As shown in Fig. 5, before training, the slope of VM versus $\dot{\mathrm{VO}}_{2}$ during the graded walking test in water was 3 -fold higher than that on land. We confirmed this also after training. Further, we confirmed that the regression equations on land in the present study were identical to those reported previously (Iwashita et al. 2003; Yamazaki et al. 2009). The reason for the higher slope in water than on land is that the accelerations in the back-forth, right-left, and up-down directions with body movement during walking decreased with rheological resistance and/or the buoyancy of water. Thus, $\mathrm{VO}_{2}$ at a given VM was higher during walking in water than on land; however, more importantly in the present study, VM was highly correlated with $\mathrm{VO}_{2}$ during walking in water as well as on land. Thus, VM can be used to estimate $\mathrm{VO}_{2}$ during walking according to the regression equations determined in each condition.

\section{Exercise intensity during IWT on land and in water}

Because $\mathrm{VO}_{2 \mathrm{GET}}$ was $\sim 0.11 \cdot \mathrm{min}^{-1}$ higher in the WG than in the LG (Table 2) and because the target intensity for fast walking during training was set as $35 \%$ higher than $\mathrm{VO}_{2 \mathrm{GET}}$ in each condition so that HR was similar between the groups (Table 2 \& Fig. 4), the exercise intensity for fast walking was $\sim 0.11 \cdot \mathrm{min}^{-1}$ higher in the WG than in the LG for the first week of training; this difference was not significant, most likely because the 
group included different subjects. A significantly higher exercise intensity for fast walking in the WG than in the LG was observed after the $4^{\text {th }}$ week (Fig. 6), which was likely caused by progressive increases in the $\dot{\mathrm{VO}}_{2 \mathrm{GET}}$, $\dot{\mathrm{VO}}_{2 \text { peak }}$ (Table 2), and thigh muscle strength values (Fig. 7) acquired by a higher intensity of training in water as confirmed after the $8^{\text {th }}$ week. As a result, the average fast walking intensity and times per day over an 8-week training period were significantly higher in the WG than in the LG (Table 3). Thus, the higher intensity of the fast walking training in the WG than in the LG was likely achieved because of the increased $\dot{\mathrm{VO}}_{2 \mathrm{GET}}$, attenuated increase in HR, and most likely therefore reduced RPE during IWT in water (Table 2 \& Fig. 4).

The discrepancy between fast walking intensity during training and target intensity

As in the Table 3, the fast walking intensity was $\sim 0.31 \cdot \mathrm{min}^{-1}$ higher than the target intensity in both groups because subjects were instructed to perform at greater than the target intensity and also because the JD Mate device did not tell them that the walking intensity exceeded the target level before calculating the mean value for the 1-min interval. In addition, because subjects were instructed to perform fast walking with 16-18 points of the Borg scale, the intensity for fast walking increased as physical fitness increased, as after the $4^{\text {th }}$ week in the WG (Fig. 6). Similarly, when physical fitness increased with training, the absolute intensity of slow walking with similar RPE sometimes exceeded the target intensity so that the time for fast walking was prolonged while that for slow walking was shortened compared with the scheduled time for each walking (Table 3). Thus, the higher level than the target intensity and the prolonged time of fast walking during training were due to the program installed in the JD Mate device and to increased physical fitness with training. 
Other possible factors causing an increase in walking intensity in the WG

The subjects in the WG may have received psychological bias from us to perform fast walking with a higher RPE than in the LG, although we paid maximal attention to avoid this. However, this bias was unlikely because, for example, as in Fig. 6, subjects in the WG performed fast walking at $108 \%$ of the pre-training $\dot{\mathrm{VO}}_{2 \text { peak }}$ for walking on land for the $1^{\text {st }}$ week of training, and, if they had performed fast walking on land at the same intensity, the HR would have increased to 153 beats $\cdot \mathrm{min}^{-1}$, which is 11 beats $\cdot \mathrm{min}^{-1}$ higher than $\mathrm{HR}_{\text {peak }}$ for walking on land, equivalent to $95 \%$ of the age-predicted maximal HR, suggesting that they would not have been able to perform fast walking at the intensity on land even if they had attempted to do it. Therefore, it is reasonable to conclude that, again, the reduction in $\mathrm{HR}$ at a given $\dot{\mathrm{VO}}_{2}$ and the upward shift of GET enabled them to perform at such a high intensity of fast walking in the WG due to reduced RPE with a high retention of subjects throughout the training period.

However, the possible effects of less feedback from sore joints and muscles due to buoyancy and less increased body temperature due to enhanced heat dissipation mechanisms in water on the higher walking intensity for the WG were not excluded in the present study.

\section{Benefits of $\dot{V} O_{2 p e a k}$ for walking determination}

It is difficult to determine maximal/peak aerobic capacity in a large population of subjects by treadmill running or cycle ergometer exercise in the field because of instrumental and personnel limitations (Fig. 1). Instead, although HR is generally used as an indicator for the target intensity of exercise training in the field (American College 
of Sports Medicine 2010), the response at a given $\mathrm{VO}_{2}$ varies according to individual physical fitness level and conditions such as dehydration, and environmental conditions such as atmospheric temperature, altitude, and whether the exercise is on land or in water, as in the present study. Therefore, to obtain the certain effects of IWT in a large population of subjects, we needed to determine $\dot{\mathrm{V}} \mathrm{O}_{2 \text { peak }}$ for walking with a graded walking test with a tri-axial accelerometer (Iwashita et al. 2003; Yamazaki et al. 2009), confirmed that the value was almost identical to that for cycling (Fig. 8), and accordingly, not a few studies regarding the effects of on-land IWT on physical fitness and the symptoms of lifestyle-related diseases have been published (Nemoto et al. 2007; Lalande et al. 2010; Morikawa et al. 2011; Nakajima et al. 2010; Zhang et al. 2015; Karstoft et al. 2013 \& 2014; Morishima et al. 2014). Based on these previous results, in the present study, we determined the target intensity for fast walking in water for middle-aged and older people planning to perform IWT in a pool to enhance their physical fitness.

\section{Perspectives}

The rapid growth in the elderly population in many countries has highlighted the importance of exercise training to decrease the likelihood of disability and age-associated diseases. In Japan, the population over 65 years old was $25.1 \%$ of the total in 2013 but will increase to over $31.6 \%$ by 2030 (Hunter et al. 2003). In such a worldwide advanced ageing society, the number of patients with knee osteoarthritis has been increasing (Felson et al. 2000; Muraki et al. 2009). Muraki et al. (2009) suggested that $\sim 70 \%$ women and $\sim 50 \%$ men aged over 65 years old in Japan suffer from knee osteoarthritis, and half of them feel difficulty in their daily physical activity because of 
knee pain. To prevent this, exercise training to increase thigh muscle strength is recommended for middle-aged and older people before they reach this age (Slemenda et al. 1998; Silva et al. 2008). However, no training regimen for middle-aged and older people to perform in water has been available because the target intensity for training is not precisely determined in water according to individual physical fitness (Kamioka et al. 2010). Therefore, IWT in water could be one of the candidates to solve the problem. In the present study, we found that 16 of 17 subjects accomplished the IWT program in a pool for 8 weeks even when the target intensity for fast walking was set at $91 \%$ of $\mathrm{VO}_{2 \text { peak }}$ for walking on land, $15 \%$ higher than that on land, so that after training, their thigh muscle strength as well as aerobic capacity increased by the similar degrees as in the previous studies on land (Morikawa et al. 2011; Nemoto et al. 2007), even within a shorter training period.

In summary, the $\dot{\mathrm{VO}}_{2 \mathrm{GET}}$ increased and $\mathrm{HR}$ at a given $\dot{\mathrm{VO}}_{2}$ decreased in middle-aged and older women during walking-in-water exercises compared with those on land, which enabled them to perform exercise at a higher metabolic rate than on land due to improved subjective feelings, which, for these subjects, resulted in greater gains in physical fitness.

\section{ACKNOWLEDGEMENTS}

This study was supported in part by grants from the Ministry of Health, Labor, and Welfare (Comprehensive Research on Ageing and Health) and the Japan Society for the Promotion of Science (24240089).

\section{CONFLICT OF INTEREST}


No conflicts of interest, financial or otherwise, are declared by the authors.

\section{REFERENCES}

American College of Sports Medicine (2010) ACSM's guidelines for exercise testing and prescription (8th ed). Lippincott Williams \& Wilkins:152-182

Bartels EM, Lund H, Hagen KB, Dagfinrud H, Christensen R, Danneskiold-Samsøe B (2007) Aquatic exercise for the treatment of knee and hip osteoarthritis. Cochrane Database Syst Rev (4):CD005523

Beaver WL, Wasserman K, Whipp BJ (1986) A new method for detecting anaerobic threshold by gas exchange. J Appl Physiol 60 (6):2020-2027

Bocalini DS, Serra AJ, Murad N, Levy RF (2008) Water- versus land-based exercise effects on physical fitness in older women. Geriatr Gerontol Int 8 (4):265-271

Christie JL, Sheldahl LM, Tristani FE, Wann LS, Sagar KB, Levandoski SG, Ptacin MJ, Sobocinski KA, Morris RD (1990) Cardiovascular regulation during head-out water immersion exercise. J Appl Physiol 69 (2):657-664

Cohen J (1988) Statistical Power Analysis for the Behavioral Sciences, Lawrence Erlbaum Associates, Publishers, Hillsdale, NJ:1-17

Connelly TP, Sheldahl LM, Tristani FE, Levandoski SG, Kalkhoff RK, Hoffman MD, Kalbfleisch JH (1990) Effect of increased central blood volume with water immersion on plasma catecholamines during exercise. J Appl Physiol 69 (2):651-656

Felson DT, Lawrence RC, Dieppe PA, Hirsch R, Helmick CG, Jordan JM, Kington RS, Lane NE, Nevitt MC, Zhang Y, Sowers M, McAlindon T, Spector TD, Poole AR, Yanovski SZ, Ateshian G, Sharma L, Buckwalter JA, Brandt KD, Fries JF (2000) Osteoarthritis: new insights. Part 1: the disease and its risk factors. Ann Intern Med 133 (8):635-646

Hall J, Grant J, Blake D, Taylor G, Garbutt G (2004) Cardiorespiratory responses to aquatic treadmill walking in patients with rheumatoid arthritis. Physiother Res Int 9 (2):59-73

Harrison R, Hillman M, Bulstrode S (1992) Loading of the lower limb when walking partially immersed: Implications for clinical practice. Physiotherapy 78 (3): $164-166$

Hunter AM, St Clair Gibson A, Lambert M, Dennis S, Mullany H, O'Malley MJ, Vaughan CL, Kay D, Noakes TD (2003) EMG amplitude in maximal and submaximal exercise is dependent on signal capture rate. Int J Sports Med 24 (2):83-89

Ide MR, Laurindo IMM, Rodrigues-Junior AL, and Tanaka C (2008) Effect of aquatic respiratory exercise-based program in patients with fibromyalgia. Int $\mathrm{J}$ Rheum Dis $11(2): 131-140$ 
Iwashita S, Takeno Y, Okazaki K, Itoh J, Kamijo Y, Masuki S, Yanagidaira Y, Nose H (2003) Triaxial accelerometry to evaluate walking efficiency in older subjects. Med Sci Sports Exerc 35 (10):1766-1772

Kamioka H, Tsutani K, Okuizumi H, Mutoh Y, Ohta M, Handa S, Okada S, Kitayuguchi J, Kamada M, Shiozawa N, Honda T (2010) Effectiveness of aquatic exercise and balneotherapy: a summary of systematic reviews based on randomized controlled trials of water immersion therapies. J Epidemiol 20 (1):2-12

Karstoft K, Winding K, Knudsen SH, James NG, Sheel MM, Olesen J, Holst JJ, Pedersen BK, Solomon TP (2014) Mechanisms behind the superior effects of interval vs continuous training on glycaemic control in individuals with type 2 diabetes: a randomized controlled trial. Diabetologia 57 (10):2081-2093

Karstoft K, Winding K, Knudsen SH, Nielsen JS, Thomsen C, Pedersen BK, Solomon TP (2013) The effects of free-living interval-walking training on glycemic control, body composition, and physical fitness in type 2 diabetic patients: a randomized, controlled trial. Diabetes Care 36 (2):228-236

Lalande S, Okazaki K, Yamazaki T, Nose H, Joyner MJ, Johnson BD (2010) Effects of interval walking on physical fitness in middle-aged individuals. J Prim Care Community Health 1 (2):104-110

Lim K, Rhi S (2014) The effects of landed and aquatic treadmill walking at moderate intensity on heart rate, energy expenditure and catecholamine. J Exerc Nutrition Biochem 18 (2):197-203

Masuki S, Mori M, Tabara Y, Miki T, Sakurai A, Morikawa M, Miyagawa K, Higuchi K, Nose H (2010) Vasopressin V1a receptor polymorphism and interval walking training effects in middle-aged and older people. Hypertension 55 (3):747-754

Masuki S, Mori M, Tabara Y, Sakurai A, Hashimoto S, Morikawa M, Miyagawa K, Sumiyoshi E, Miki T, Higuchi K, Nose H (2015) The factors affecting adherence to a long-term interval walking training program in middle-aged and older people. J Appl Physiol 118 (5):595-603

Morikawa M, Okazaki K, Masuki S, Kamijo Y, Yamazaki T, Gen-no H, Nose H (2011) Physical fitness and indices of lifestyle-related diseases before and after interval walking training in middle-aged and older males and females. Br J Sports Med 45 (3):216-224

Morishima Y, Mizushima T, Yamauchi K, Morikawa M, Masuki S, Nose H (2014) Effects of home-based interval walking training on thigh muscle strength and aerobic capacity in female total hip arthroplasty patients: a randomized, controlled pilot study. PLoS One 9 (9):e108690

Muraki S, Oka H, Akune T, Mabuchi A, En-yo Y, Yoshida M, Saika S, Suzuki T, Yoshida H, Ishibashi H, Yamamoto S, Nakamura K, Kawaguchi H, Yoshimura N (2009) Prevalence of radiographic knee osteoarthritis and its association with knee pain in the elderly of Japanese population-based cohorts: The ROAD study. Osteoarthritis Cartilage 17 (9):1137-1143

Nakajima K, Takeoka M, Mori M, Hashimoto S, Sakurai A, Nose H, Higuchi K, Itano N, 
Shiohara M, Oh T, Taniguchi S (2010) Exercise effects on methylation of ASC gene. Int J Sports Med 31 (9):671-675

Nemoto K, Gen-no H, Masuki S, Okazaki K, Nose H (2007) Effects of high-intensity interval walking training on physical fitness and blood pressure in middle-aged and older people. Mayo Clin Proc 82 (7):803-811

Nose H, Morikawa M, Yamazaki T, Nemoto K, Okazaki K, Masuki S, Kamijo Y, Gen-No H (2009) Beyond epidemiology: field studies and the physiology laboratory as the whole world. J Physiol 587 (Pt 23):5569-5575

Park KS, Choi JK, Park YS (1999) Cardiovascular regulation during water immersion. Appl Human Sci 18 (6):233-241

Sanders ME, Takeshima N, Rogers ME, Colado JC, Borreani S (2013) Impact of the S.W.E.A.T. ${ }^{\mathrm{TM}}$ water-exercise method on activities of daily living for older women. J Sports Sci Med 12 (4): 707-715

Silva LE, Valim V, Pessanha AP, Oliveira LM, Myamoto S, Jones A, Natour J (2008) Hydrotherapy versus conventional land-based exercise for the management of patients with osteoarthritis of the knee: a randomized clinical trial. Phys Ther 88 (1): $12-21$

Slemenda C, Heilman DK, Brandt KD, Katz BP, Mazzuca SA, Braunstein EM, Byrd D (1998) Reduced quadriceps strength relative to body weight: a risk factor for knee osteoarthritis in women? Arthritis Rheum 41 (11):1951-1959

Takeshima N, Rogers ME, Watanabe E, Brechue WF, Okada A, Yamada T, Islam MM, Hayano J (2002) Water-based exercise improves health-related aspects of fitness in older women. Med Sci Sports Exerc 34 (3):544-551

Tsourlou T, Benik A, Dipla K, Zafeiridis A, Kellis S (2006) The effects of a twenty-four-week aquatic training program on muscular strength performance in healthy elderly women. J Strength Cond Res 20 (4):811-818

Yamazaki T, Gen-No H, Kamijo Y, Okazaki K, Masuki S, Nose H (2009) A new device to estimate VO2 during incline walking by accelerometry and barometry. Med Sci Sports Exerc 41 (12):2213-2219

Zhang Y, Hashimoto S, Fujii C, Hida S, Ito K, Matsumura T, Sakaizawa T, Morikawa M, Masuki S, Nose H, Higuchi K, Nakajima K, Taniguchi S (2015) NFkB2 gene as a noble candidate epigenetically responding to interval walking training. Int $\mathrm{J}$ Sports Med 36 (9):769-775 


\section{FIGURE LEGENDS}

\section{Fig. 1:}

Our experimental strategy for the present study during the last decade. First, to extend exercise training for middle-aged and older people according to individual fitness level from a gym/laboratory to the field, we developed the graded walking test to determine peak aerobic capacity $\left(\dot{\mathrm{VO}}_{2 \text { peak }}\right)$ for walking using a tri-axial accelerometer (Iwashita et al., 2003; Yamazaki et al., 2009), and then, based on the values, we instructed them to perform interval walking training (IWT) on land and confirmed that the effects (Masuki et al., 2010 \& 2015; Morikawa et al., 2011; Nemoto et al., 2007) were almost equivalent to those of machine training (American College of Sports Medicine 2010). The purpose of the present study was to determine the target intensity for those who are planning to perform IWT in water to enhance physical fitness.

\section{Fig. 2:}

A timeline of the experiment. IWT, interval walking training; LG, a group performing IWT on land; WG, a group performing IWT in water. Each group was divided into the $1^{\text {st }}$ and $2^{\text {nd }}$ subgroups, starting IWT in April and August, 2013, respectively, due to instrumental and personnel limitations.

\section{Fig. 3:}

Fig. 3 (A) shows a trend graph of the heart rate (HR), oxygen consumption rate $\left(\mathrm{VO}_{2}\right.$, $\left.1 \cdot \mathrm{min}^{-1}\right)$, carbon dioxide production rate $\left(\mathrm{VCO}_{2}\right)$ every $10 \mathrm{sec}$ in a subject during the graded walking test in water and on land. R, rest; S, slow; M, moderate; and F, the fastest speed of walking. An upward arrow indicates $\dot{\mathrm{VO}}_{2 \text { peak }}$ for walking on land and a 
downward arrow indicates the $\dot{\mathrm{VO}} 2$ value for walking in water equal to the $\dot{\mathrm{VO}}_{2 \text { peak }}$ on land. We named the values as "the highest common $\mathrm{VO}_{2}$ " observed in both conditions. We compared HR at the highest $\dot{\mathrm{VO}}_{2}$ between the conditions. Fig. 3 (B) shows HR and $\dot{\mathrm{VCO}}_{2}$ responses to $\dot{\mathrm{VO}}_{2}$ during the graded walking tests in water and on land. The gas exchange threshold (GET) in water was determined by V slope method (Beaver et al.

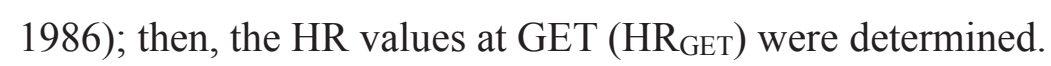

\section{Fig. 4:}

Heart rate $(\mathrm{HR})$ at a given oxygen consumption $\left(\dot{\mathrm{VO}}_{2}, 1 \cdot \mathrm{min}^{-1}\right)$ at rest, the gas exchange threshold (GET), the highest common $\dot{\mathrm{VO}}_{2}$ observed in both conditions (Highest $\dot{\mathrm{VO}}_{2}$ ). The individual and mean values of HR for 16 subjects for the WG are shown for the on-land trial (open circles) and for the in-water trial (closed circles). The corresponding $\dot{\mathrm{VO}}_{2}$ values are shown as the mean values for the on-land (open column) and the in-water (closed column) trials. *, **, Significant differences versus on-land trial at $\mathrm{P}<$ 0.05 and $\mathrm{P}<0.01$, respectively.

\section{Fig. 5:}

Relationship between the oxygen consumption rate $\left(\mathrm{VO}_{2}, \mathrm{ml} \cdot \mathrm{kg}^{-1} \cdot \mathrm{min}^{-1}\right)$ and the vector magnitude of tri-axial accelerations (VM) during graded walking tests on land and in a pool (water) before IWT. The values of 31 subjects from the WG and the LG in the land trial and the values of 16 subjects in the water trial from the WG for the last $30 \mathrm{sec}$ of rest, slow, moderate, and the fastest walking periods ( $3 \mathrm{~min}$ each) were pooled. See text for a description of the regression analyses. Regression lines (solid lines) and area for 95\% confidence limits (dotted lines) are shown. 


\section{Fig. 6:}

Fast walking exercise intensity measured on the last walking day of every week during training. The means and SE bars include the results of 16 subjects in the WG and 15 subjects in the LG. $\uparrow, \uparrow \uparrow$, Significant differences in the $\dot{\mathrm{VO}}_{2}$ between the WG and the LG, at $\mathrm{P}<0.05$, and $\mathrm{P}<0.01 ; \# \#$ significant interactive effects of [training weeks $\mathrm{x}$ groups] on the $\mathrm{VO}_{2}$ for the fast walking at $\mathrm{P}<0.01$.

\section{Fig. 7:}

Isometric knee extension ( $\left.\mathrm{F}_{\mathrm{EXT}}\right)(\mathbf{A})$ and flexion $\left(\mathrm{F}_{\mathrm{FLX}}\right)(\mathbf{B})$ forces before and after training, presented as the means and SE bars including the results from 16 and 15 subjects in the WG and the $\mathrm{LG}$, respectively. ***Significant differences versus the pre-training values for each group at $\mathrm{P}<0.001$; \#, \#\#, significant interactive effects of [before and after training $\mathrm{x}$ groups] on the $\dot{\mathrm{VO}}_{2 \mathrm{GET}}$ for cycling, $\mathrm{F}_{\mathrm{EXT}}$, or $\mathrm{F}_{\mathrm{FLX}}$ at $\mathrm{P}<0.05$ and $\mathrm{P}<0.01$, respectively.

\section{Fig. 8:}

Relationship between peak oxygen consumption rate $\left(\dot{\mathrm{VO}}_{2 \text { peak }}\right)$ for walking on land versus that for cycling in the water (WG) and land (LG) groups before and after training. A regression line (a solid line) and an area for 95\% confidence limits (dotted lines) are shown. 


\section{Experimental strategy}

A gym (traditional methods)

$\dot{\mathrm{V}}_{2 \text { peak }}$ determination with gas analyzer by graded cycling and Exercise training using bicycle treadmill exercise

Problems Limited availability \& high cost

Solutions

\section{Field ( on land)}

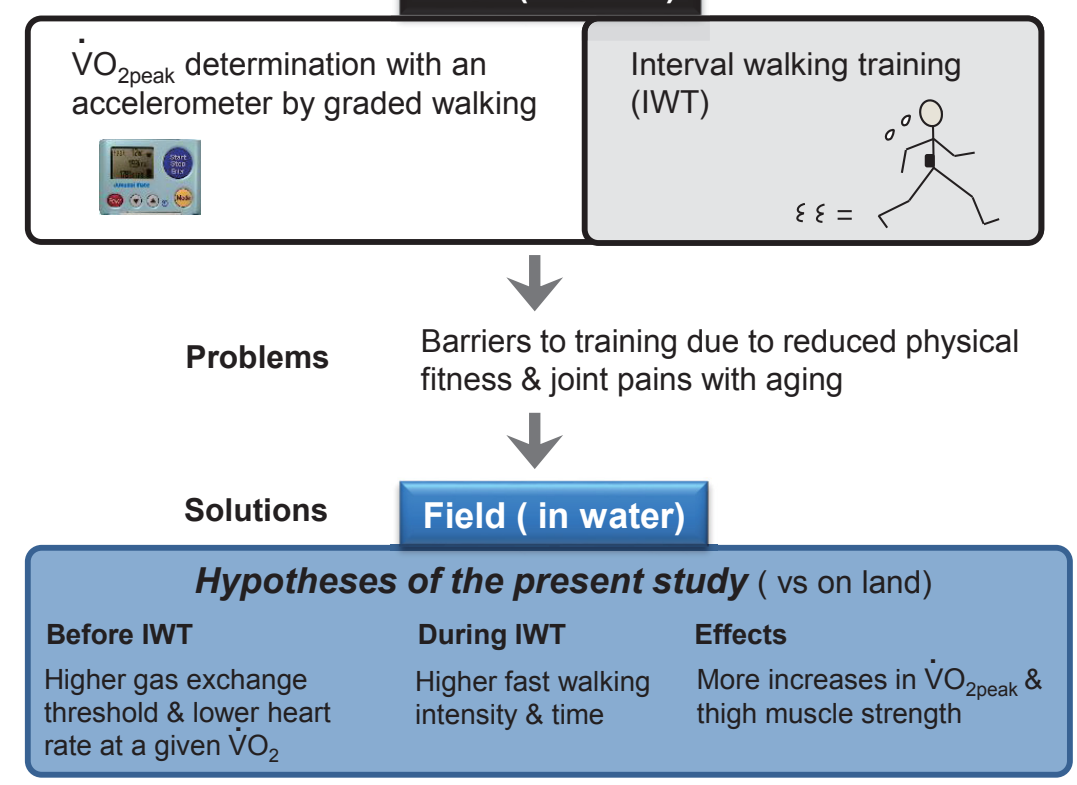

Figure 1, Handa et al. 
Announcement to 10,600 household in Tomi with a bullet of city, March 2013

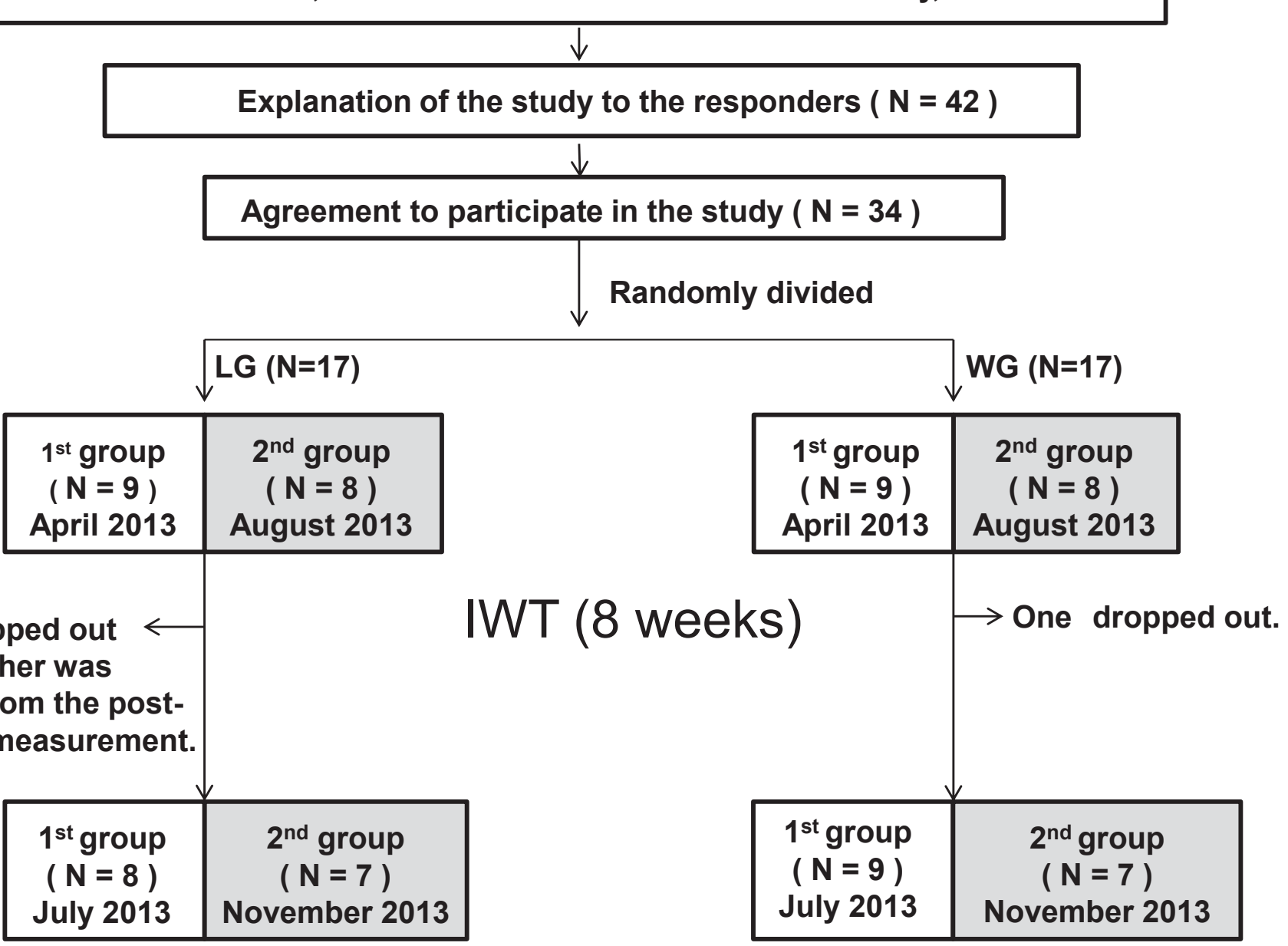

One dropped out and another was absent from the posttraining measurement.

\begin{tabular}{|c|c|}
\hline $1^{\text {st }}$ group & $2^{\text {nd }}$ group \\
$(\mathrm{N}=\mathbf{8})$ & $(\mathrm{N}=7)$ \\
July 2013 & November 2013 \\
\hline
\end{tabular}

\begin{tabular}{|c|c|}
\hline $1^{\text {st }}$ group & $2^{\text {nd }}$ group \\
$(\mathrm{N}=9)$ & $(\mathrm{N}=7)$ \\
July 2013 & November 2013 \\
\hline
\end{tabular}

Figure 2, Handa et al. 


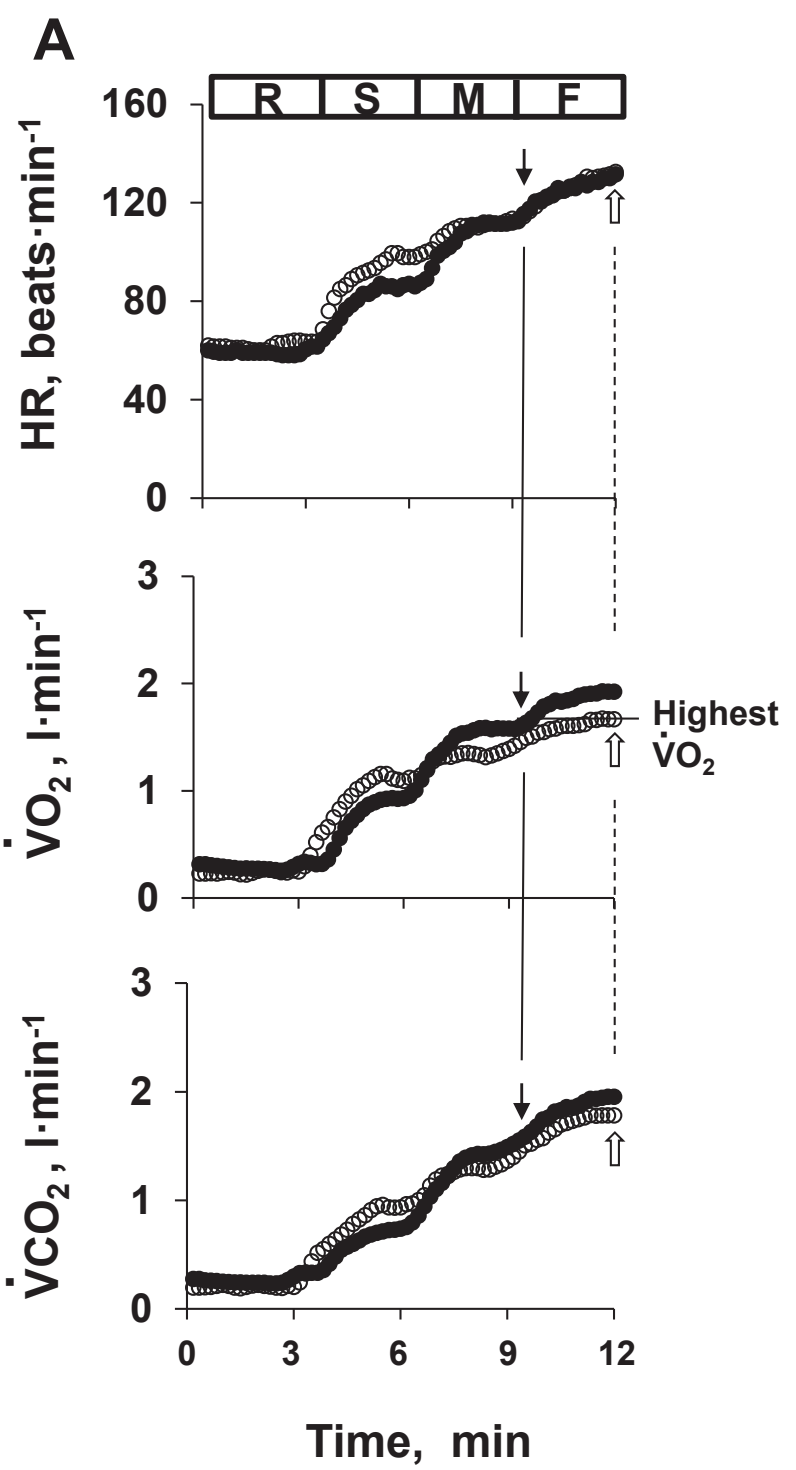

B

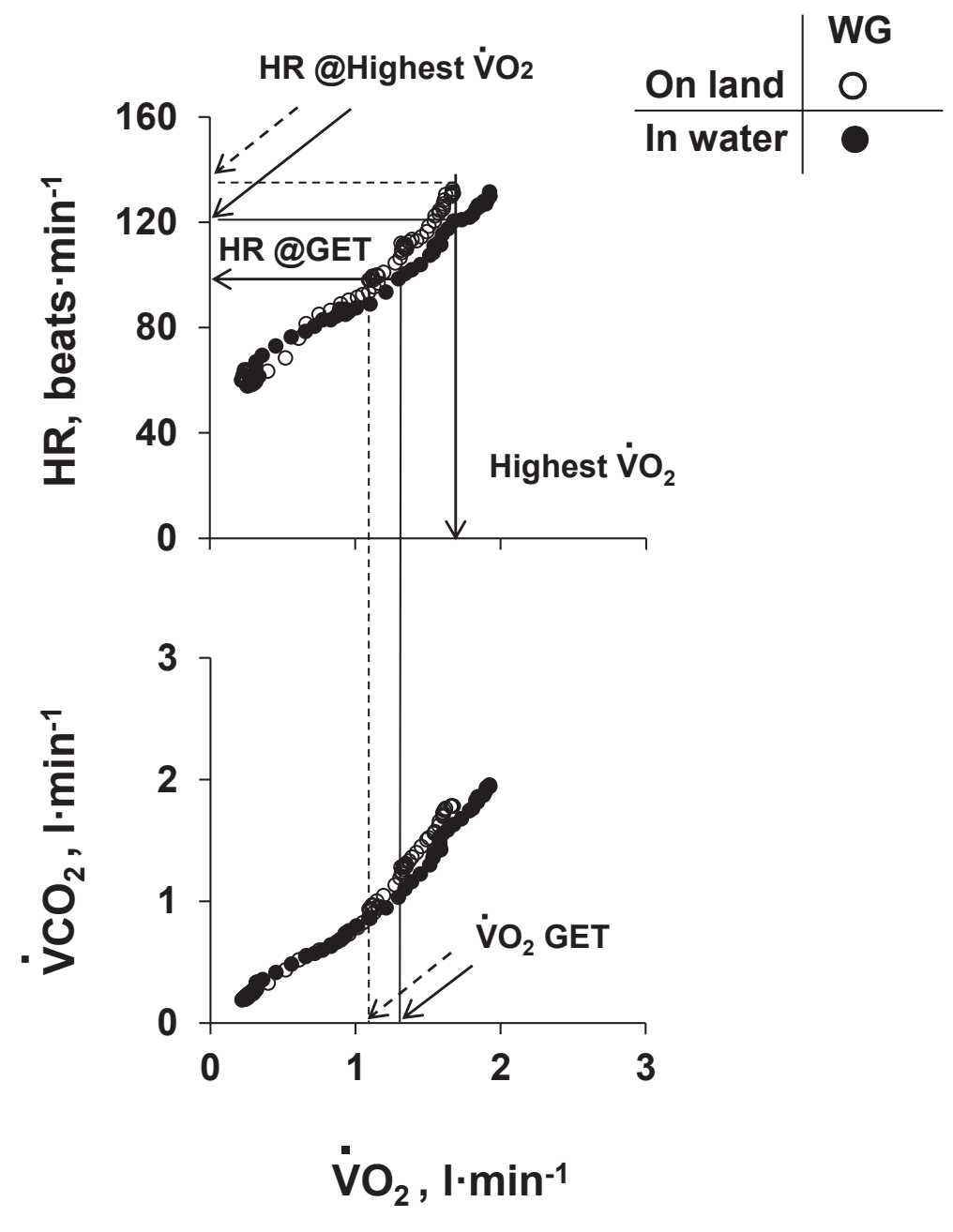

Figure 3, Handa et al. 

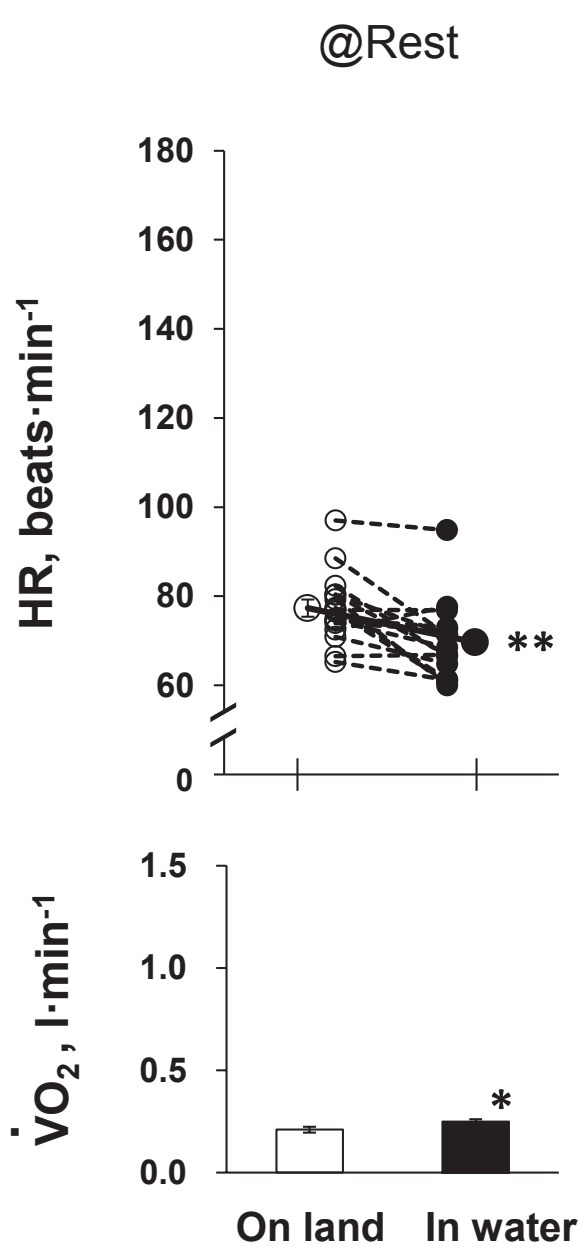
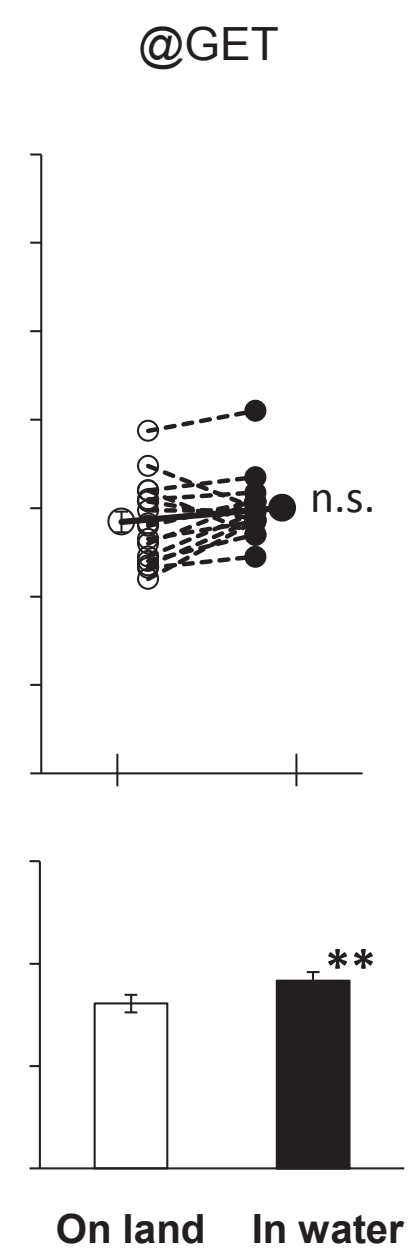

@Highest $\dot{\mathrm{V}} 2$
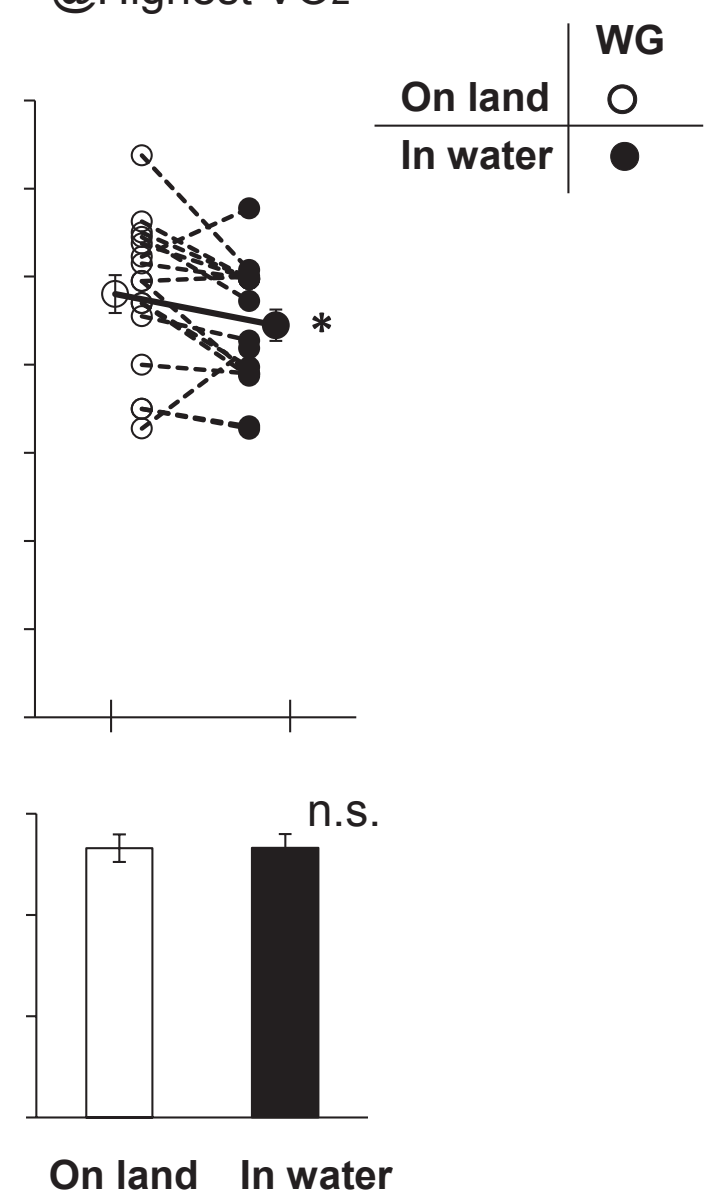

Figure 4, Handa et al. 


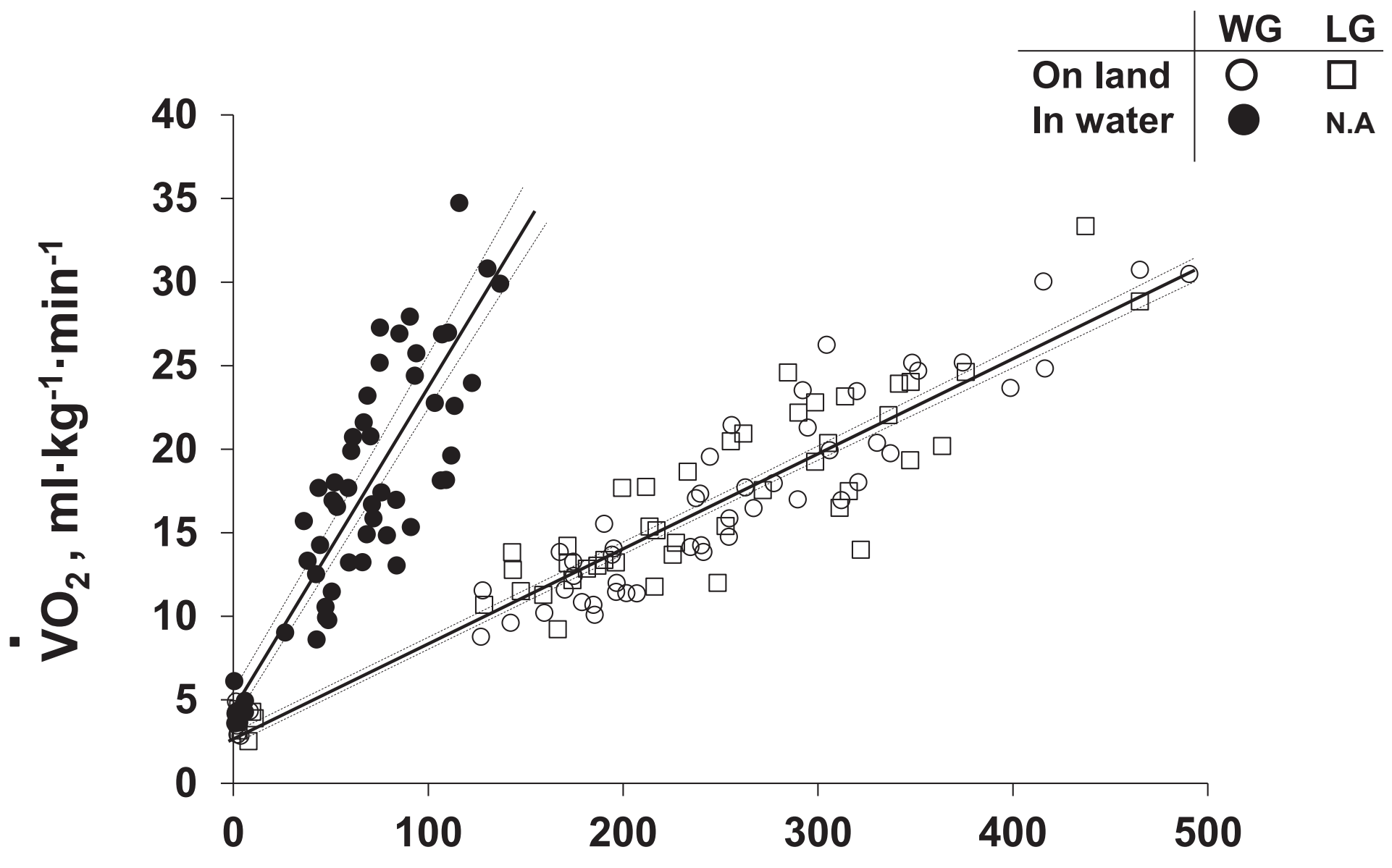

VM, G

Figure 5, Handa et al. 


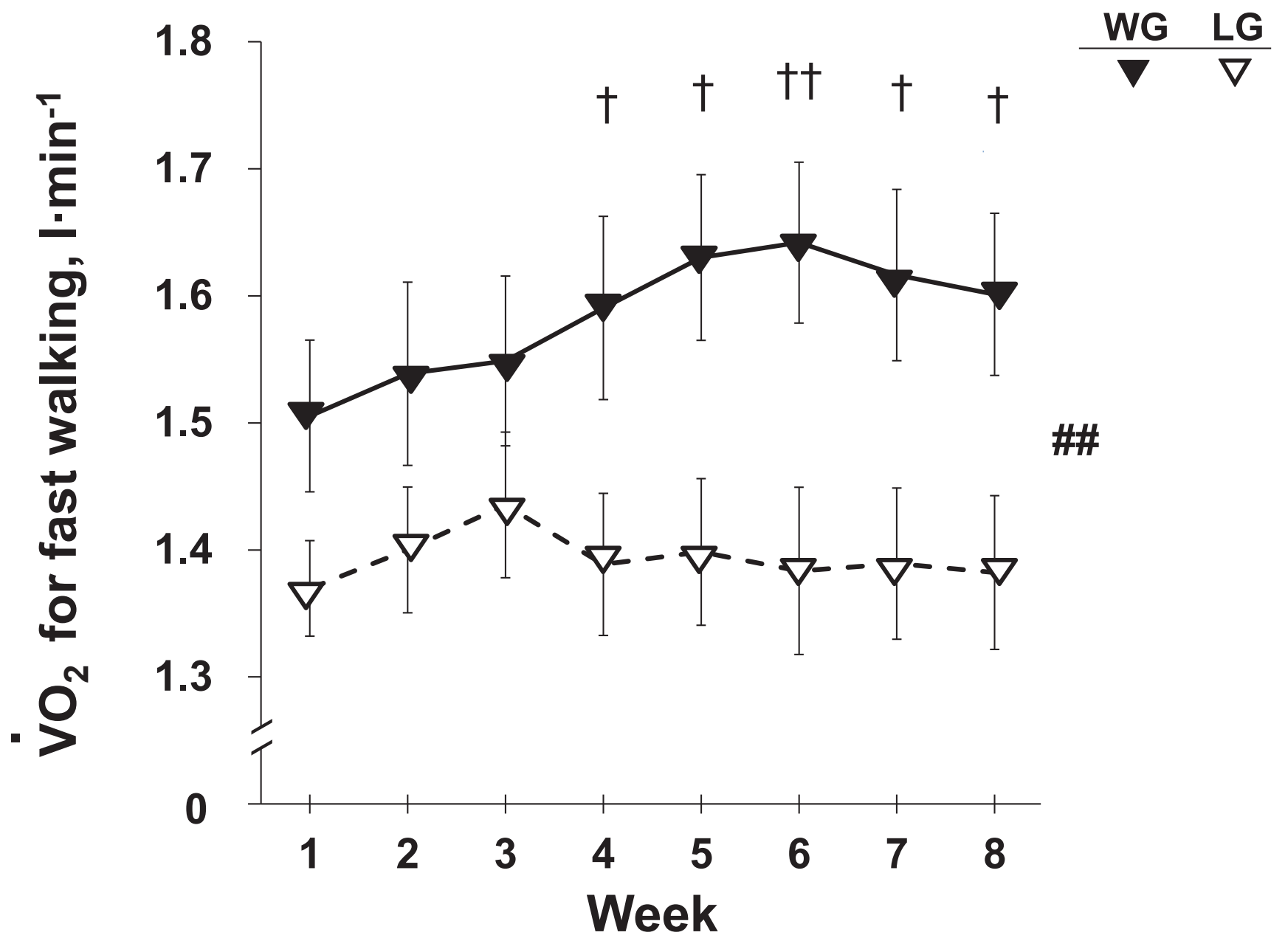

Figure 6, Handa et al. 


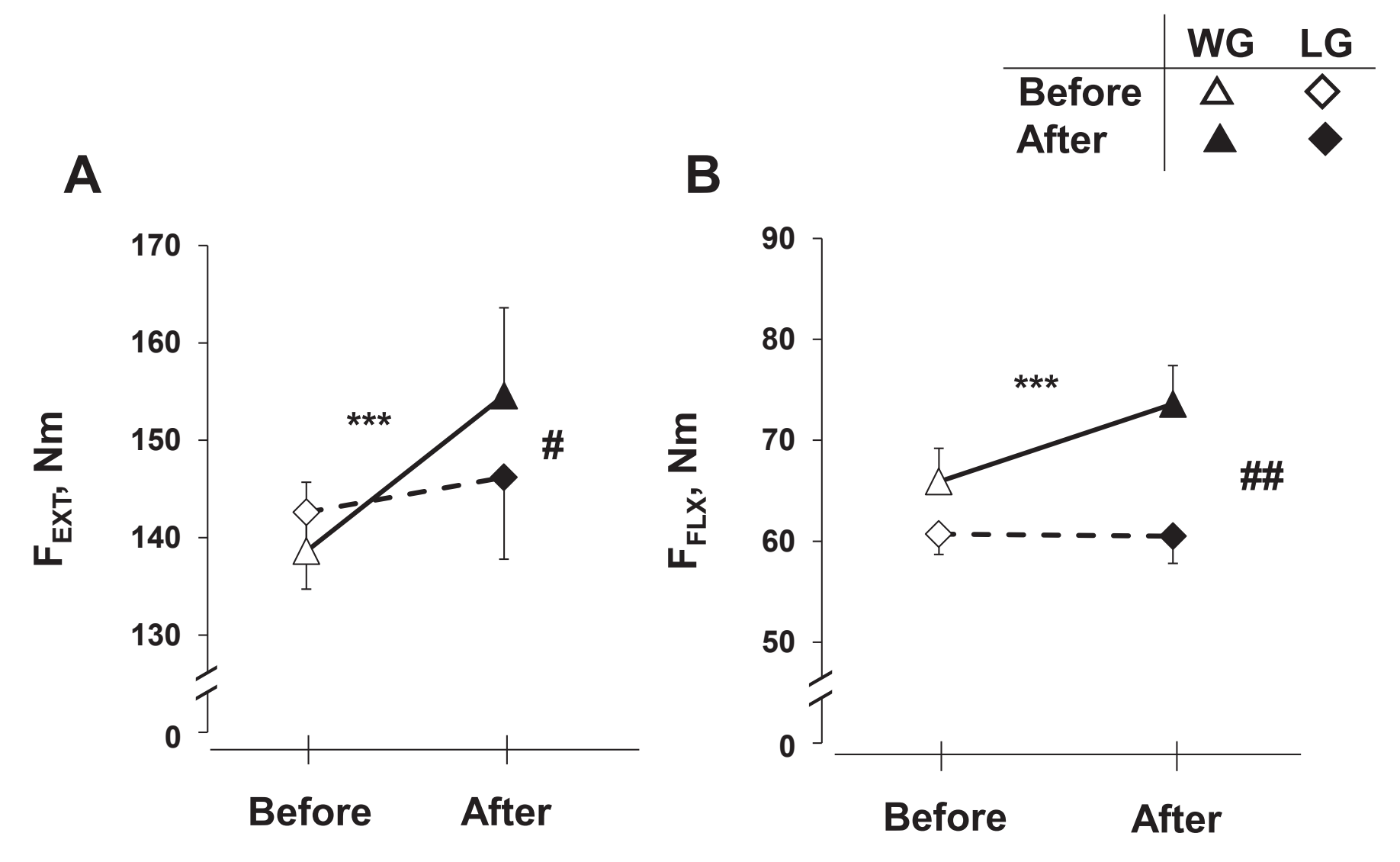

Figure 7, Handa et al. 


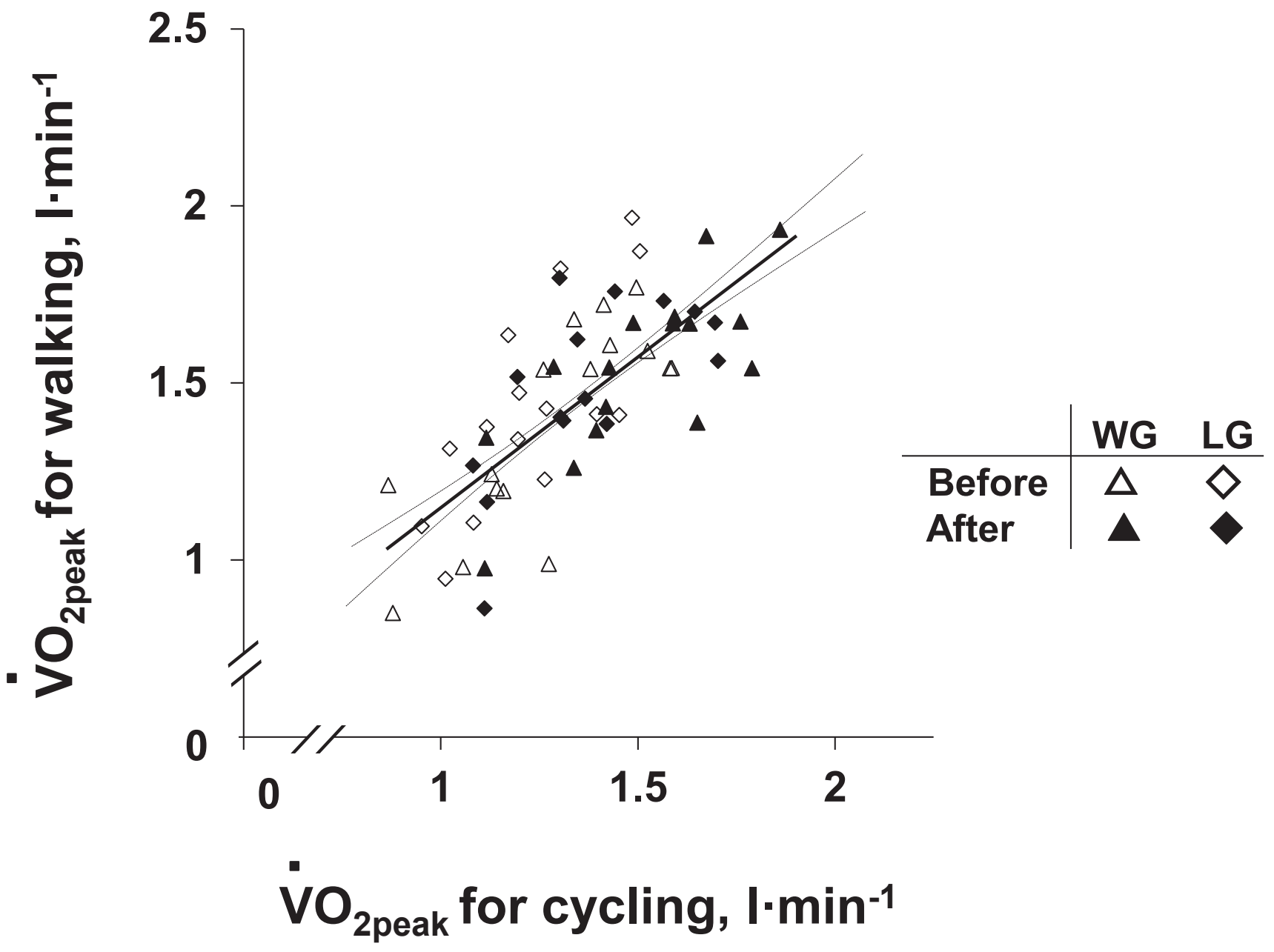

Figure 8, Handa et al. 
Table 1: Physical characteristics of subjects before and after training

\begin{tabular}{|c|c|c|c|c|c|c|c|c|c|c|c|c|c|c|}
\hline \multirow[b]{3}{*}{ Age, yr } & \multicolumn{7}{|c|}{$\mathbf{L G}(N=15)$} & \multicolumn{6}{|c|}{ WG $(N=16)$} & \multirow{2}{*}{$\begin{array}{c}\text { 2-Way ANOVA } \\
\begin{array}{c}\text { P values for } \\
\text { interaction }\end{array}\end{array}$} \\
\hline & \multicolumn{3}{|c|}{ Before } & \multicolumn{4}{|c|}{ After } & \multicolumn{2}{|c|}{ Before } & \multicolumn{3}{|c|}{ After } & & \\
\hline & 59.4 & \pm & 1.4 & & - & & & $59.4 \pm$ & 1.5 & & - & & & - \\
\hline Height, cm & 157.6 & \pm & 1.3 & & - & & & $158.6 \pm$ & 0.9 & & - & & & - \\
\hline Body mass, kg & 59.1 & \pm & 1.7 & 58.2 & \pm & 1.6 & $* *$ & $59.5 \pm$ & 2.9 & 58.8 & \pm & 2.7 & $*$ & 0.535 \\
\hline $\mathrm{BMI}, \mathrm{kg} \cdot \mathrm{m}^{-2}$ & 23.8 & \pm & 0.6 & 23.4 & \pm & 0.6 & $* *$ & $23.6 \pm$ & 1.1 & 23.3 & \pm & 1.0 & $*$ & 0.472 \\
\hline Body fat, \% & 32.1 & \pm & 1.5 & 30.6 & \pm & 1.1 & $*$ & $29.4 \pm$ & 1.9 & 28.3 & \pm & 1.8 & & 0.634 \\
\hline $\mathrm{SBP}, \mathrm{mmHg}$ & 126.5 & \pm & 4.3 & 123.9 & \pm & 5.2 & & $124.1 \pm$ & 5.1 & 116.3 & \pm & 3.5 & & 0.444 \\
\hline $\mathrm{DBP}, \mathrm{mmHg}$ & 78.4 & \pm & 3.5 & 75.7 & \pm & 4.0 & & $74.4 \pm$ & 3.1 & 69.9 & \pm & 2.1 & & 0.638 \\
\hline
\end{tabular}

BMI, body mass index; SBP, systolic blood pressure; DBP, diastolic blood pressure. Mean \pm standard error (SE) in groups performing 8 -week interval walking training on land (LG) and in water $(\mathrm{WG})$, respectively. ${ }^{*}$ and $* *$ represent significant differences versus before training in each group at $\mathrm{P}<$ 0.05 and $\mathrm{P}<0.01$, respectively. The $\mathrm{P}$ values for interaction indicate the presence of a significant interactive effect of $[($ before and after training) $\mathrm{x}$ group]. 
Table 2: $\mathrm{HR}$ and $\dot{\mathrm{VO}}_{2}$ at peak exercise intensity during graded walking and cycling tests before and after training

\begin{tabular}{|c|c|c|c|c|c|c|c|c|c|c|c|c|c|c|c|c|c|c|}
\hline & & \multicolumn{8}{|c|}{ LG (N=15) } & \multicolumn{8}{|c|}{ WG $(\mathrm{N}=16)$} & \multirow{2}{*}{$\begin{array}{c}\text { 2-Way ANOVA } \\
\text { P values for } \\
\text { Interaction }\end{array}$} \\
\hline & & \multicolumn{4}{|c|}{ Before } & \multicolumn{3}{|c|}{ After } & & \multicolumn{3}{|c|}{ Before } & \multicolumn{4}{|c|}{ After } & & \\
\hline \multirow[t]{4}{*}{ L-walking } & $\mathrm{HR}_{\text {peak }}$, beats $\cdot \mathrm{min}^{-1}$ & 140 & \pm & 3 & & 138 & \pm & 4 & & 142 & \pm & 4 & & 146 & \pm & 4 & & 0.306 \\
\hline & $\mathrm{VO}_{2 \text { peak }}, 1 \cdot \mathrm{min}^{-1}$ & 1.43 & \pm & 0.08 & & 1.49 & \pm & 0.07 & & 1.39 & \pm & 0.07 & & 1.54 & \pm & 0.06 & $* *$ & 0.227 \\
\hline & $\mathrm{HR}_{\mathrm{GET}}$, beats $\cdot \mathrm{min}^{-1}$ & 96 & \pm & 2 & & 95 & \pm & 3 & & 97 & \pm 2 & 2 & & 98 & \pm & 3 & & 0.513 \\
\hline & $\mathrm{VO}_{2 \mathrm{GET}}, 1 \cdot \mathrm{min}^{-1}$ & 0.81 & \pm & 0.04 & & 0.86 & \pm & 0.06 & & 0.81 & \pm & 0.04 & & 0.93 & \pm & 0.04 & $* *$ & 0.170 \\
\hline \multirow[t]{4}{*}{ Cycling } & $\mathrm{HR}_{\text {peak}}$, beats $\cdot \mathrm{min}^{-1}$ & 142 & \pm & 3 & & 146 & \pm & 3 & $\dagger$ & 149 & \pm & 4 & $\dagger$ & 150 & \pm & 3 & & 0.308 \\
\hline & $\mathrm{VO}_{2 \text { peak }}, 1 \cdot \mathrm{min}^{-1}$ & 1.23 & \pm & 0.05 & $\dagger$ & 1.37 & \pm & 0.05 & $* * * \dagger$ & 1.28 & \pm & 0.06 & $\dagger$ & 1.51 & \pm & 0.06 & $* * *$ & 0.015 \\
\hline & $\mathrm{HR}_{\mathrm{GET}}$, beats $\cdot \mathrm{min}^{-1}$ & 100 & \pm & 3 & & 96 & \pm & 3 & & 102 & \pm & 4 & & 101 & \pm & 4 & & 0.436 \\
\hline & $\mathrm{VO}_{2 \mathrm{GET}}, 1 \cdot \mathrm{min}^{-1}$ & 0.76 & \pm & 0.04 & & 0.80 & \pm & 0.03 & & 0.75 & \pm & 0.04 & & 0.86 & \pm & 0.05 & $* * *$ & 0.030 \\
\hline \multirow[t]{4}{*}{ W-walking } & $\mathrm{HR}_{\text {peak }}$, beats $\cdot \mathrm{min}^{-1}$ & & - & & & & - & & & 139 & \pm & 4 & & 138 & \pm & 4 & $\dagger$ & \\
\hline & $\mathrm{VO}_{2 \text { peak }}, 1 \cdot \mathrm{min}^{-1}$ & & - & & & & - & & & 1.44 & \pm & 0.08 & & 1.61 & \pm & 0.08 & $* * \dagger$ & \\
\hline & $\mathrm{HR}_{\mathrm{GET}}$, beats $\cdot \mathrm{min}^{-1}$ & & - & & & & - & & & 100 & \pm 2 & 2 & & 103 & \pm & 2 & $\dagger$ & \\
\hline & $\mathrm{VO}_{2 \mathrm{GET}}, 1 \cdot \mathrm{min}^{-1}$ & & - & & & & - & & & 0.92 & \pm & 0.04 & $H$ & 1.06 & \pm & 0.04 & $* * * \dagger \dagger$ & \\
\hline
\end{tabular}

L-walking, graded walking test on land; Cycling, graded cycling test on land; $\mathrm{W}$-walking, graded walking test in water; $\mathrm{HR}_{\text {peak, }}$ peak heart rate; $\mathrm{VO}_{2 \text { peak, }}$ peak 
oxygen consumption rate; $\mathrm{HR}_{\mathrm{GET}}$, heart rate (HR) at the GET; $\dot{\mathrm{VO}}_{2 \mathrm{GET}} \dot{\mathrm{VO}}_{2}$ at the gas exchange threshold (GET). Mean $\pm \mathrm{SE}$ in the groups. ** and *** versus the values before training in each group at $\mathrm{P}<0.01$, and $\mathrm{P}<0.001$, respectively. $\dagger$, $\dagger \dagger$, and $\dagger \dagger \dagger$ versus the values in $\mathrm{L}$-walking at $\mathrm{P}<0.05, \mathrm{P}<0.01$, and $\mathrm{P}<0.001$, respectively. The $\mathrm{P}$ values for interaction indicate the presence of a significant interactive effect of [(before and after training) $\mathrm{x}$ group]. Other abbreviations are the same as in Table 1. 
Table 3: Training achievements

\begin{tabular}{|c|c|c|c|c|c|c|c|}
\hline \multirow[b]{2}{*}{ Total walking days } & \multicolumn{3}{|c|}{ LG $(n=15)$} & \multicolumn{3}{|c|}{ WG $(n=16)$} & \\
\hline & 31.2 & \pm & 0.8 & 31.1 & \pm & 0.9 & \\
\hline Walking days $\cdot$ week $^{-1}$ & 3.9 & \pm & 0.1 & 3.9 & \pm & 0.1 & \\
\hline \multicolumn{8}{|l|}{ Fast walking } \\
\hline Time, min $\cdot$ walking day ${ }^{-1}$ & 18.1 & \pm & 0.8 & 25.6 & \pm & 2.3 & $* *$ \\
\hline$\S$ Intensity, $1 \cdot \min ^{-1}$ & 1.40 & \pm & 0.05 & 1.59 & \pm & 0.06 & $*$ \\
\hline \multicolumn{8}{|l|}{ Slow walking } \\
\hline Time, min $\cdot$ walking day ${ }^{-1}$ & 18.4 & \pm & 1.2 & 11.5 & \pm & 2.3 & $*$ \\
\hline$\S$ Intensity, $1 \cdot \mathrm{min}^{-1}$ & 0.73 & \pm & 0.04 & 1.09 & \pm & 0.05 & $* * *$ \\
\hline Total $\dot{\mathrm{VO}}_{2}, 1$ & 1213 & \pm & 57 & 1657 & \pm & 85 & $* * *$ \\
\hline
\end{tabular}

Values presented as the mean $\pm \mathrm{SE}$ in each group. *,**, and *** versus the values in $\mathrm{LG}$ at $\mathrm{P}<0.05, \mathrm{P}<0.01$, and $\mathrm{P}<0.001$, respectively. Other abbreviations are the same as in Table 1. §Resting oxygen consumption is included. 